Seth Dworkin, Qingan Zhang, Murray J. Thomson, Nadezhda A. Slavinskaya, Uwe Riedel

Application of an Enhanced PAH Growth Model to Soot Formation in a Laminar Coflow Ethylene/Air Diffusion Flame

Combustion and Flame, 2011,158 (9), 1682-1695

The original publication is available at www.elsevier.com http://dx.doi.org/10.1016/j.combustflame.2011.01.013 


\section{Application of an Enhanced PAH Growth Model to Soot Formation in a Laminar Coflow Ethylene/Air Diffusion Flame}

Seth B. Dworkin, phone: 1 (416) 946-7743

Qingan Zhang ${ }^{1}$, phone: 1 (403) 284-7464

Murray J. Thomson, phone: 1 (416) 580-3391

Department of Mechanical and Industrial Engineering University of Toronto

5 King's College Circle

Toronto, Ontario, Canada, M5S 3G8

Nadezhda A. Slavinskaya, phone: +49-711-6862-543

Uwe Riedel, phone: +49-711-6862-351

Institute of Combustion Technology

German Aerospace Centre (DLR)

Pfaffenwaldring 38-40

70569, Stuttgart, Germany

\section{Corresponding Author:}

M. J. Thomson

Department of Mechanical and Industrial Engineering University of Toronto

5 King's College Circle

Toronto, Ontario M5S 3G8, Canada

(416) 946-7743 (W)

(416) $978-7753$ (FAX)

thomson@mie.utoronto.ca

\footnotetext{
${ }^{1}$ Has moved to Oil Sands Development and Research, Imperial Oil Resources, 3535 Research Road NW Calgary, AB, T2L 2K8, Canada
} 


\begin{abstract}
:
A recently developed chemical kinetic scheme for $\mathrm{C}_{2}$ fuel combustion with $\mathrm{PAH}$ growth has been implemented in a parallelized coflow flame solver. The reaction mechanism has been developed to include almost all now reasonably well-established reaction classes for aromatic ring formation and soot particle precursor molecular weight growth. The model has recently been validated for zero- and one-dimensional premixed flame systems [N.A. Slavinskaya and P. Frank, Combust. Flame, 156, (2009) 1705-1722] and has now been updated and extended to a sooting ethylene/air diffusion flame in the coflow geometry. Updates to the mechanism reflect the latest advances in the literature and address numerical stiffness that was present in diffusion flame systems. The chemical kinetic mechanism has been coupled to a sectional aerosol dynamics model for soot growth, considering PAH-based inception and surface condensation, surface chemistry (growth and oxidation), coagulation, and fragmentation. The sectional model predicts the soot aggregate number density and the number of primary particles per aggregate in each section, so as to yield information on particle size distribution and structure. Flame simulation data for the present mechanism is compared to data computed using two other reaction schemes ([J. Appel, H. Bockhorn, M. Frenklach, Combust. Flame, 121 (2000) 122-136] and [N.M. Marinov, W.J. Pitz, C.K. Westbrook, A.M. Vincitore, M.J. Castaldi, S.M. Senkan Combust. Flame, 114 (1998) 192-213]). The computed data are also compared to numerous experimental data sets. Whereas the fuel oxidation chemistry in all three mechanisms are essentially the same, the PAH growth pathways vary considerably. It is shown that soot concentrations on the wings of the flame (where soot formation is dominated by surface chemistry) can be predicted with two of the three mechanisms. However, only the present mechanism with its enhanced PAH growth routes can also predict the correct order of magnitude of soot volume fraction in the low-sooting, inception-dominated, central region of the flame. In applying this chemical mechanism, the parameter $\alpha$, which described the portion of soot surface sites that are available for chemical reaction, has been reduced to a theoretically acceptable range, thus improving the quality of the model.
\end{abstract}

Keywords: coflow diffusion flame, PAH growth, soot formation, ethylene, parallel computation 


\section{Introduction and background}

High concentrations of combustion-generated soot in the atmosphere are known to pose significant health risks, cause cloud and contrail formation, and contribute to long-term global climate change. A detailed fundamental understanding of soot formation and growth could aid researchers and engineers in designing fuels, engines, and power generation systems that are cleaner and emit less particulate into our atmosphere. Although much progress has been made, a complete understanding of soot formation in combustion still eludes researchers.

In order to accurately model soot formation in combustion simulation algorithms, numerous mechanisms which contribute to overall soot concentration need to be considered. These include polycyclic aromatic hydrocarbon (PAH) growth/particle inception, surface growth via surface chemistry and via PAH condensation, surface oxidation, particle coagulation and fragmentation, gas phase scrubbing, and radiation [1]. Some of these processes, in particular PAH growth and soot particle inception, are poorly understood and difficult to model. Inception depends on local concentrations of aromatic species, the size of which depend on the fuel being burned $[1,2,3]$. The chemical kinetics of these large molecules involve hundreds of intermediate chemical species and thousands of reaction steps [4].

Although present computer models of soot formation are known to be incomplete, and still contain semi-empirical assumptions, much has been learned from computer simulation of sooting flames. For this reason, numerous researchers have strived to develop more and more accurate models for combustion and soot formation. The majority of works that have achieved quantitative accuracy in soot formation in laminar flames have coupled a chemical kinetic mechanism including PAHs to an approximated soot growth model such as sectional aerosol dynamics $[5,6]$ or the method of moments [7].

\subsection{Background on soot model and PAH mechanism development}

A large and impressive body of work has come from Frenklach and coworkers (see, for example, $[8,9,10,11,12])$ focusing on premixed flames, PAH growth, and utilizing the method of moments. In particular, two seminal works demonstrated that (1) mass growth of PAH soot precursors up to pyrene could be modeled using the hydrogen-abstraction-acetylene-addition (HACA) mechanism [10], and (2) the same HACA growth principles could be applied to the surface of soot particles, which are structurally similar to PAHs, to account for soot growth to within the correct order of magnitude for a variety of laminar premixed flames of $\mathrm{C}_{2}$ hydrocarbons [11]. The PAH growth mechanism used in [11] was primarily based on the chemistry set from [10] but also included $\mathrm{C}_{4} \mathrm{H}_{4}$ and acenaphthalene reactions. This work shows that within the poorly known boundaries of certain soot formation parameters, such as the fraction of soot surface sites available for chemical reaction, soot formation data can be made to agree reasonably well with experiment. Appel et al. [11] further point out that such agreement in soot concentration can be achieved despite difficulties in modeling large aromatic soot precursor concentrations in the few systems where experimental data was available. Two recent works by Guo and Smallwood [13], and Guo et al. [14] also utilize the method of moments and address underprediction of PAH concentrations using an "ad hoc" method of unphysically reducing the scrubbing of pyrene in the gaseous mixture, thereby violating conservation of mass by creating pyrene in the gas-phase. As Guo et al. [14], for example, have been able to achieve accurate soot concentrations with this method, the need and potential to address insufficient PAH formation are welldemonstrated.

Smooke and coworkers have had success using the sectional model to study soot formation in diffusion flames. In steady $[15,16,17,18,19]$ and transient systems [20], inception was based on the 
formation rates of naphthalene and phenanthrene, which were estimated using simplified steady-state expressions that depended on acetylene, benzene, phenyl, and molecular hydrogen concentrations [18]. This novel technique eliminated the need to include PAH growth in the chemical kinetic mechanism, thus reducing computational cost and eliminating the uncertainty of an incomplete or incorrect PAH growth mechanism. However, the disadvantages of this approach were that (1) PAH condensation could not be directly included in the simulations and (2) the assumption that soot inception was directly proportional to the formation rates of naphthalene and phenanthrene is relatively untested. Good agreement with experimental data for soot concentrations was demonstrated on the wings of a steady ethylene/air flame but significant underprediction of soot concentration was noted in the central region of the flame. Smooke et al. [17] noted that the errors were likely attributable to uncertainties in modeling PAH growth and inception in this region. Such uncertainties were not effecting soot concentrations as significantly on the wings of the flame, where growth is dominated by surface chemistry.

An equally impressive body of work by D'Anna, Kent, and coworkers in the last decade has looked at aromatic formation, primarily in ethylene [21] and methane [22] diffusion flames, adding a considerable amount of PAH growth pathways from benzene to naphthalene including cyclopentadienyl combination and propargyl addition, in addition to standard HACA. Those first two works were extended to include soot modeling [23,24,25]. Results obtained in [21] agreed well with the experimental data sets for two different ethylene/air flames; one studied first by McEnally and Pfefferle [26] and one by Santoro et al. [27]. However, despite overprediction of acetylene and benzene in [23] and "soot precursors" in [24] in the central region of the flame, soot formation was underpredicted by their model in the central region of the flames as well.

In the last few years, Zhang and coworkers have extended the sectional aerosol dynamics model to track both particle diameter and number of primary particles per aggregate in each section so as to yield information on particle size distribution and structure. This model was first applied to ethylene/air diffusion flames [28,29,30], and more recently to a jet fuel flame [31]. These studies used the chemical kinetic mechanism, pyrene-based inception, soot surface chemistry, and surface condensation models from [11]. When compared to the experimental data set of Santoro et al. [27], it was shown that peak soot values and radial profiles at select heights could be well reproduced in the ethylene system. In the jet fuel system, the soot model was unchanged, and despite known interractions between fuel components and aromatic growth that were unaccounted for in the mechanism, peak soot and radial profiles in lower regions of the flame agreed reasonable well with experiment [31]. In both flames, however, centerline soot concentrations were underpredicted by an order of magnitude or more. Fortunately, the highly detailed set of information yielded by the two-equation-per-section soot model showed that the average primary particle diameter along the centerline was much lower than in other more heavily sooting regions of the flame. This suggests that surface growth is occuring at a much lower rate in the central region, confirming the observations in a similar system by Smooke et al. [17]. It is worth noting that although Zhang and coworkers have employed a functional form of $\alpha$, the fraction of soot surface sites available for chemical reaction, taken from $\mathrm{Xu}$ et al. [32], the value of $\alpha$ yielded by that form for temperatures less than $1955 \mathrm{~K}$ is 1.0 and varies from 1.0 to 0.77 for temperatures between $1955 \mathrm{~K}$ and $2055 \mathrm{~K}$ (the maximum temperature reached in the ethylene/air diffusion flame). Therefore, in most of the flame region, the number of active surface sites available for chemical reaction is quite close to the theoretical maximum value of available soot surface sites [11]. This is evidence that if particle inception could be enhanced to achieve physically accurate values of soot volume fraction in the inception-dominated central region of the flame, some surface chemistry could be suppressed by lowering $\alpha$ within a physically acceptable range.

This collection of studies, including the simultaneous underprediction of pyrene concentration with correct order-of-magnitude prediction of soot concentration in the premixed flames in [11], the 
centerline underpredictions of soot volume fraction by Smooke and coworkers [16,17,18], and the central region underpredictions by Zhang and coworkers [28,29,30,31], all point to the difficulty of correctly modeling PAH growth up to large aromatics and particle inception. Further, the studies also suggest that physically accurate values of peak soot concentrations can still be obtained due to their insensitivity to PAH growth and particle inception. This has been achieved by boosting soot surface chemistry rates with poorly known parameters such as $\alpha$, the fraction of surface sites available for chemical reaction. The preponderance of simulation studies mentioned above suggests the need to revisit the study of PAH growth and soot inception, such that both surface growth-dominated and inception-dominated flame regions can be modeled using as few assumptions as possible and physically realistic values of $\alpha$. This advancement would result in the ability of soot models to correctly predict soot concentrations in flame regions where soot formation is not surface growth-dominated, and would increase the fidelity of predictions in flame regions where soot formation is surface growthdominated.

It is clear that detailed and accurate PAH growth mechanisms are necessary if accurate simulation of particle inception, and specifically, of soot formation in inception-dominated combustion regimes are desired. As such, there has been a substantial increase in the number of PAH mechanism studies, especially in the last fifteen years. In addition to key works mentioned above by Frenklach and Coworkers [10,11] modeling growth up to pyrene, and D'Anna, Kent, and coworkers [21,22] modeling growth up to naphthalene, Böhm and coworkers have looked at PAH growth in acetylene and benzene pyrolysis [33,34] and in counterflow diffusion flames burning methane [35]. These works consider methyl, propargyl, cyclopendadienyl, and aryl addition pathways for large PAHs [34] and clearly demonstrate the importance of numerous growth pathways in an opposed flow methane diffusion flame [35].

Recently, Slavinskaya and Frank [36] proposed a mechanism for $\mathrm{C}_{1}$ and $\mathrm{C}_{2}$ fuel combustion and PAH growth up to five-ring aromatics. Their collection of species and reactions was based on a survey of the literature of the last 30 years and includes numerous pathways not previously considered important to soot precursor modeling. In addition to HACA growth, and other reactions involving cyclobutadiene, acenaphthalene, biphenyl, cyclopentadiene, and indenyl, the mechanism considers hydrogen atom migration, free radical addition schemes, methyl substitution pathways, cyclopentadienyl moiety in aromatic ring formation, and numerous reactions between aromatic radicals and stable aromatic molecules. The small radicals: $\mathrm{CH}_{3}, \mathrm{C}_{2} \mathrm{H}, \mathrm{C}_{2} \mathrm{H}_{3}, \mathrm{H}_{2} \mathrm{CCCH}, \mathrm{C}_{3} \mathrm{H}_{4}, \mathrm{C}_{4} \mathrm{H}, \mathrm{H}_{2} \mathrm{CCCCH}$, $\mathrm{C}_{4} \mathrm{H}_{5}, \mathrm{C}_{5} \mathrm{H}_{5}$ and small molecules: $\mathrm{C}_{2} \mathrm{H}_{2}, \mathrm{C}_{4} \mathrm{H}_{2}, \mathrm{C}_{4} \mathrm{H}_{4}, \mathrm{C}_{6} \mathrm{H}_{2}$ were used as "building blocks" for PAH molecule growth and for the $\mathrm{H}$ atom abstraction from hydrocarbons. In the present manuscript, the mechanism has been modified and extended to coflow ethylene/air diffusion flames. In a companion manuscript [37], the modified mechanism is described in detail and applied to opposed flow diffusion flames of ethylene and ethane. Some Arrhenius rates and thermodynamic data have been recalculated to account for numerical stiffness that was present in diffusion systems, while the integrity of the mechanism with regard to premixed combustion was carefully maintained. In [37], results were compared to data computed using two other mechanisms (Appel et al. [11] and Marinov et al. [38]), and to the experimental data sets of Vincitore and Senkan [39] for ethane combustion, and Olten and Senkan [40] for ethylene combustion. It was shown that while bulk flame properties and major species profiles were the same for the three mechanisms, the enhanced PAH growth routes were necessary to numerically predict the correct order of magnitude of PAHs that were measured in the experimental studies. In the present study, the updated mechanism is used to predict soot precursor concentrations, and is coupled to the soot model via soot inception, surface condensation, surface chemistry, and gas phase scrubbing. 


\subsection{Coflow flame parallelization}

This type of computational study involving detailed chemical kinetic mechanisms with a sophisticated soot model and flame solver is possible in no small part due to the computational advantages provided by parallel computing. In the past few years, parallelization of coflow laminar diffusion flame algorithms has shifted from a topic of fundamental study and development to a necessary tool for the generation and management of simulation data. Early studies used very few computer processing units (CPUs) by today's standards and focused on generating and quantifying the efficiency of computational work distribution schemes, while solving "test case" problems for which known solutions could be generated in serial and used for comparison. For example, in 1991, Smooke and Giovangigli [41] computed a laminar methane/air diffusion flame using strip domain decomposition over 6 CPUs. Since then, numerous similar studies that have developed and tested either strip- or block-domain decomposition algorithms and have laid the foundation for the highly efficient parallel flame simulation algorithms that are currently in use (see, for example $[28,42,43,44,45,46,47,48])$.

Due in large part to the advent of inexpensive computing power, these parallelization strategies have now been extended to comparatively large numbers of CPUs and a new realm of problems, previously intractable in serial processing are now being solved (see, for example, [20] in which 40 CPUs are used, [31] in which 192 CPUs are used, and [49] in which 1167 CPUs are used). The present work utilizes the same algorithm as in [31], again with 192 CPUs. Although problems with the computational complexity of those in the current study could be computed on far fewer CPUs as in [28], the increased parallelization permits numerous fast computations to be performed for the purposes of greater analysis and comparison, such as multiple computations of the same flame with different chemical kinetic mechanisms, or studying the effect of varying the parameter $\alpha$, as mentioned in Section 1.1.

\subsection{Agenda}

In the next section, the burner and flame configuration, and the flame model are described. Then, the three chemical kinetic mechanisms that are used in the present study are outlined and contrasted. Section 3 presents the numerical methods and parallel implementation strategy that are used, along with results of a parallel scaling study that was conducted for two of the three mechanisms. Computed results with the three mechanisms, comparisons to experimental data, and discussion are found in Section 4. Finally, a summary and conclusions, as well as some future perspectives are highlighted in Section 5.

\section{Problem Formulation}

\subsection{Burner and flame description}

The present study aims to simulate the atmospheric pressure, non-smoking, coflow laminar ethylene/air diffusion flame, first studied by Santoro et al. [27]. This particular flame has been chosen for the present study because there is a significant body of literature devoted to it, including a wealth of experimental data for model validation $[27,50,51,52,53,54,55,56,57,58]$, and it has many characteristics that make it amenable to detailed numerical simulation. These characteristics include its use of ethylene, its non-smoking, yet sooting nature, and its confinement to the laminar regime. A schematic representation of the burner, flame, and computational domain are depicted in Fig 1. 
Pure ethylene gas enters the flame domain via the central fuel tube, which has an inner diameter of $11.1 \mathrm{~mm}$. Air enters the flame domain via a coflowing annular region with an inner diameter of $102.0 \mathrm{~mm}$. A ceramic honeycomb structure is typically used to straighten the air flow so that it can be well approximated by a flat profile. However, less certainty exists about the fuel flow profile. Simulations were conducted using both parabolic and flat fuel profiles and results were found to be insensitive to the choice of fuel velocity profile. Therefore, a flat profile is used in the present study. Both the fuel and air flows are at atmospheric temperature and pressure, although some heating of the fuel tube and fuel flow does occur. The flow configuration generates a stable, sooting, non-smoking flame, with a visible flame height of approximately $88 \mathrm{~mm}$.

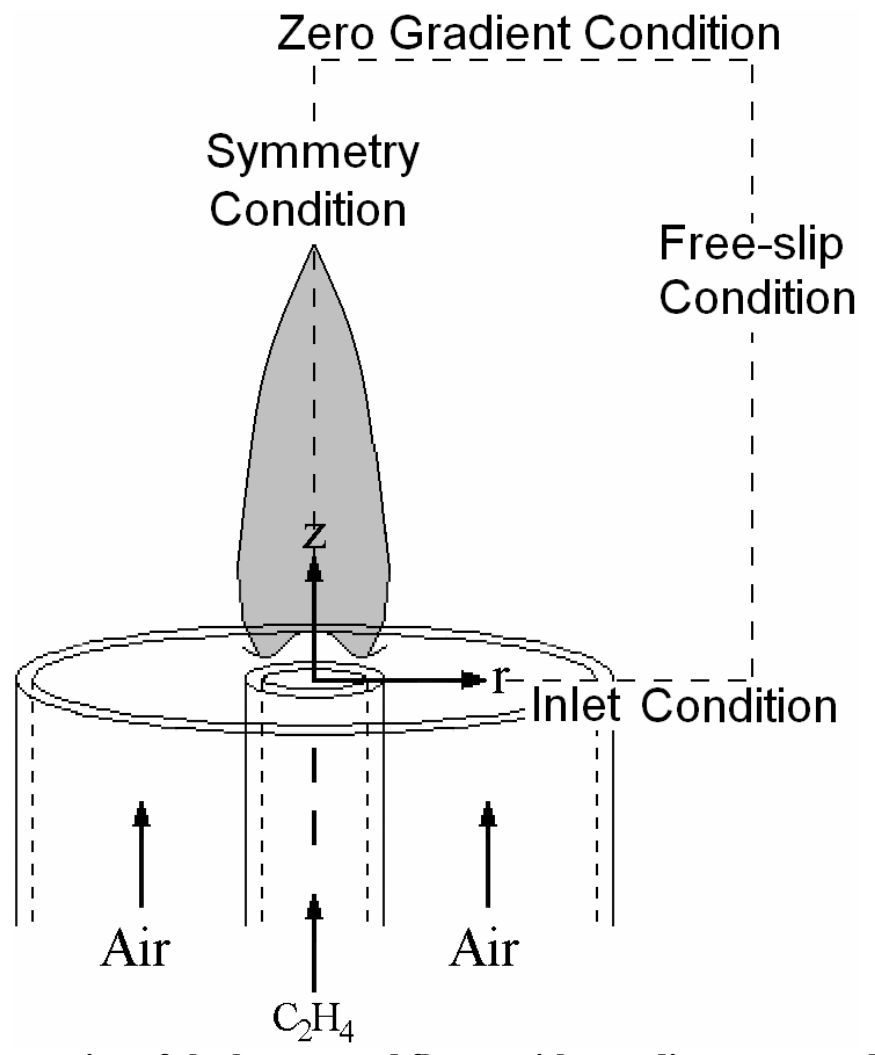

Fig. 1. Schematic representation of the burner and flame, with coordinate axes and computational domain boundaries. (Image is not drawn to scale.)

Despite the non-ideal preheating of the fuel flow, this flame was chosen in part due to the wealth of experimental data available for validation from studies spanning the last three decades. In 1983, Santoro et al. [27] applied laser extinction to measure centreline and radial profiles of soot volume fraction, axial profiles of centreline, maximum, and integrated soot volume fraction, and radial profiles of particle number concentration and particle diameter. Megaridis and Dobbins [51,52] combined thermophoretic sampling measurements with data from [27] to determine specific soot surface growth rates, soot surface area, and primary particle number densities along the pathline of maximum soot. In 1993, Puri et al. [53] added fractal dimension to the data set using a laser scattering extinction technique and simultaneous measuring of light scattering at different angles. Of particular interest in the present study is the work by Köylü et al. [54], which compares centreline soot volume fraction profiles determined from laser extinction [27], thermocouple particle densitometry [54], and thermophoretic sampling [56]. All three measurement techniques agreed in values of soot volume fraction between 1 and $6 \mathrm{ppm}$ at axial positions between 30 and $80 \mathrm{~mm}$ above the burner surface. This data highlighted modeling deficiencies in previous studies [30], in which predicted centerline soot 
volume fractions peaked at $0.1 \mathrm{ppm}$. Further studies have continued to apply thermophoretic sampling and transmission electron microscope techniques [57], and refined studies of primary particle diameter and number densities [58].

\subsection{Model description}

The gas phase model solves the fully coupled elliptic conservation equations for mass, momentum, energy, species mass fractions, soot aggregate number densities, and primary particle number densities. Due to the cylindrically symmetric nature of the problem, the governing equations are cast in a two-dimensional axisymmetric cylindrical coordinate system. The governing equations and boundary conditions can be found in [59].

Soot particle dynamics are modeled using a fixed sectional approach in which the soot particle mass range is divided logarithmically into thirty-five discrete sections. Each soot aggregate is assumed to comprise equally sized spherical primary particles with a constant fractal dimension of $1.8[60,61]$ and is assigned to a section depending on its size. For each section, two transport equations are solved; one for primary spherical particle number density, and one for soot aggregate density. Development of the two-equation-per-section model is detailed in [62] and [63], and the transport equations, in cylindrical axisymmetric form (as used in the present study), are presented in [28] and [29]. The soot sectional model considers nucleation, surface growth, PAH surface condensation, surface oxidation, coagulation, fragmentation, particle diffusion, thermophoresis, and particle radiation. By processes that increase particle size, such as coagulation and surface growth, aggregates migrate from lower sections to higher sections. Conversely, processes that decrease particle size, such as oxidation and fragmentation will cause particles to migrate from higher sections to lower sections

The nucleation step is based on the collisions of two pyrene molecules in the free-molecular regime and therefore connects the gaseous pyrene concentrations with the smallest particle size section. Care is taken to ensure species mass and energy conservation; Thus inception acts as a negative source term for the species conservation equation for pyrene, in addition to being a positive source term for the sectional equations, and the net difference in enthalpy from the destruction of pyrene and the generation of particles is accounted for as a source term in the energy equation. The surface chemistry model considers growth via the HACA mechanism developed in [64], and soot size reduction via oxidation [65]. Surface growth via PAH condensation is calculated by considering collisions between pyrene molecules and soot aggregates of any size [11]. Based on a detailed analysis, the probability of sticking in each PAH-soot collision, $\gamma$ is set to 0.5 [29]. Mass and energy conservation are duly accounted for with surface chemistry and condensation in an analogous fashion to that described above for particle inception. A source term is considered in the energy equation due to the nongray radiative heat transfer by soot, as well as $\mathrm{H}_{2} \mathrm{O}, \mathrm{CO}_{2}$, and $\mathrm{CO}$, and is calculated using the discrete-ordinates method and a statistical narrow-band correlated- $k$-based model developed by Liu et al. [66].

\subsection{PAH mechanisms}

Three different chemical kinetic mechanisms; Appel et al. [11], Marinov et al. [38], and the present mechanism adapted from Slavinskaya and Frank [36], will be used with the model described above. The detailed chemical kinetic model of Marinov et al. [38] was used to investigate aromatic and PAH formation pathways in a rich, sooting, $n$-butane-oxygen-argon burner stabilized flame, and had previously been developed for rich, premixed, methane, ethane, ethylene, and propane flames [67]. The mechanism considers methyl substituted aromatics, two-ring, three-ring, four-ring and five-ring fused aromatic structures, but detailed reaction pathways were only included for $\mathrm{PAH}$ formation up to $\mathrm{C}_{15} \mathrm{H}_{\mathrm{x}}$ aromatic rings. The reaction pathways leading to larger molecules, i.e. pyrene $\left(\mathrm{C}_{16} \mathrm{H}_{10}\right)$, 
benzo(ghi)fluoranthene $\left(\mathrm{C}_{18} \mathrm{H}_{10}\right), \quad c$-penta(cd)pyrene $\left(\mathrm{C}_{18} \mathrm{H}_{10}\right)$, and $4 \mathrm{H}-c$-penta(def)phenanthrene $\left(\mathrm{C}_{15} \mathrm{H}_{10}\right)$ were highly approximated, characterised by the authors as a "mechanistic road map", mostly with only one reaction step per pathway.

In addition to the standard HACA growth mechanism, Marinov et al. considered several reaction steps involving the combination of resonantly stabilized free radicals (propargyl, allyl, 1methylallenyl, cyclopentadienyl and indenyl) to model PAH growth. These radicals were identified as the important aromatic and PAH precursor species that combine with each other, leading to benzene, toluene, xylene, naphthalene, and phenanthrene. The propargyl recombination reaction was determined to be the dominant pathway to benzene formation. Reactions involving resonantly stabilized cyclopentadienyl and indenyl radicals were shown to be important for the formation of naphthalene and phenanthrene. The modeling results in $[38,67]$ showed that PAH formation may be promoted by small amounts of $\mathrm{O}_{2}$ rather than inhibited, as it was previously believed on the basis of HACA growth. Reaction rates for the PAH chemistry in $[38,67]$ were adopted from literature or experimental data, estimated using analogous reactions, and optimised for the modeling of laminar flames.

In contrast to the Marinov et al. model [38], which considers many odd-carbon-atom species pathways, the PAH growth mechanism of Appel et al. [11] is mostly acetylene $\left(\mathrm{C}_{2} \mathrm{H}_{2}\right)$ based. The mechanism of Appel et al. [11] has been developed based on a detailed reaction scheme for PAH formation and growth up to pyrene $\left(\mathrm{C}_{16} \mathrm{H}_{10}\right)$, first presented by Wang and Frenklach [10] for laminar premixed acetylene and ethylene flames. The formation of the first aromatic rings, benzene and phenyl, was described by reactions of $\mathrm{C}_{4} \mathrm{H}_{x}$ species with acetylene, cyclization reactions of $\mathrm{C}_{6} \mathrm{H}_{x}$ species, and by the self-combination of propargyl. The growth of PAH species essentially follows the HACA sequence, extended with reactions of PAH molecules with ethynyl radical, aromatic molecule isomerisation, and ring-ring "condensation" reactions (mostly for biphenyl formation). In [11] the authors made revisions to the PAH gas-phase component of the model in [10] and applied it to nine different laminar premixed flames of ethane, ethylene, and acetylene. The gas-phase mechanism revisions in [11] considered the addition of hydrogen atom migration, the ring-forming addition of vinylacetylene $\left(\mathrm{C}_{4} \mathrm{H}_{4}\right)$ to aromatic radicals (followed by an $\mathrm{H}$-abstraction), the ring-ring "condensation" reactions for phenanthrene formation, and the formation of acenaphthalen. The Appel et al. mechanism [11] includes fewer aromatic species compared to the Marinov et al. mechanism [38] and considers neither indene chemistry, nor some of the reactions of resonantly stabilised radicals. Simplifications in the Appel et al. mechanism [11] led to the underpredictions of aromatic species concentrations. To compensate, the rates of aromatic cyclization through acetylene addition were doubled, and some growth reactions, most importantly propargyl self-combination, were made irreversible, which can result in serious distortions in the reaction fluxes.

The recently proposed reaction mechanism of Slavinskaya and Frank [36], was developed to predict the formation of PAHs up to five aromatic rings in methane and ethane-fueled flames. The model is based on the $\mathrm{C}_{0}-\mathrm{C}_{2}$ chemistry of $[68,69]$ with recently revised and well-established chemical kinetic data. The mechanism of PAH formation was deduced with the aim of describing the formation of aromatics up to $\mathrm{C}_{20}$ and their radicals, which have been detected in non-negligible concentrations in flame experiments involving $\mathrm{CH}_{4}, \mathrm{C}_{2} \mathrm{H}_{4}$, and $\mathrm{C}_{2} \mathrm{H}_{6}$. These species are benzene (A1), toluene $\left(\mathrm{C}_{7} \mathrm{H}_{8}\right)$, phenylacetylene $\left(\mathrm{A} 1 \mathrm{C}_{2} \mathrm{H}\right)$, styrene $\left(\mathrm{A} 1 \mathrm{C}_{2} \mathrm{H}_{3}\right)$, indene $\left(\mathrm{C}_{9} \mathrm{H}_{8}\right)$, naphthalene (A2), biphenyl, (P2), acenaphthylene (A2R5), phenanthrene (A3), pyrene (A4), benzo(ghi)-fluoranthene, (BGHIF), chrysene $\left(\mathrm{C}_{18} \mathrm{H}_{12}\right)$, benzo(a)py-rene, (BAPYR) and some of their branched structures and radicals (see Fig. 2 and 3).

The reaction routes for aromatic production have been synthesized by analysing the data reported in the literature during the last thirty years. All reasonably well-established routes from small aliphatic molecules to first aromatic rings and pre-particle molecular weight growth were considered: HACA mechanism; hydrogen atom migration yielding the five- and six- member rings; interconversion 
of five- and six- member rings and zigzag aromatic edges; resonantly stabilized free radical addition schemes; methyl substitution / acetylene addition pathways; cyclopentadienyl moiety in aromatic ring formation; and reactions between aromatic radicals and molecules. The small radicals: $\mathrm{CH}_{3}, \mathrm{C}_{2} \mathrm{H}$, $\mathrm{C}_{2} \mathrm{H}_{3}, \mathrm{H}_{2} \mathrm{CCCH}, \mathrm{C}_{3} \mathrm{H}_{4}, \mathrm{C}_{4} \mathrm{H}, \mathrm{H}_{2} \mathrm{CCCCH}, \mathrm{C}_{4} \mathrm{H}_{5}, \mathrm{C}_{5} \mathrm{H}_{5}$ and small molecules: $\mathrm{C}_{2} \mathrm{H}_{2}, \mathrm{C}_{4} \mathrm{H}_{2}, \mathrm{C}_{4} \mathrm{H}_{4}, \mathrm{C}_{6} \mathrm{H}_{2}$ were used as "building blocks" for $\mathrm{PAH}$ molecule growth and for H-atom abstraction from hydrocarbons. Hydrogen atom migration was considered as part of the HACA reaction set. Important reaction pathways for aromatic molecule growth are shown in Fig. 2 and 3. The resulting mechanism was tested against experimental data measured for laminar premixed $\mathrm{CH}_{4}$ and $\mathrm{C}_{2} \mathrm{H}_{4}$ flames at atmospheric pressure or in shock tube experiments under elevated pressure by twelve independent research groups. The simulated flame speeds, temporal profiles of small and large aromatics, and soot volume fraction data agreed well with experimental data obtained for different temperatures, mixing ratios and diluents.

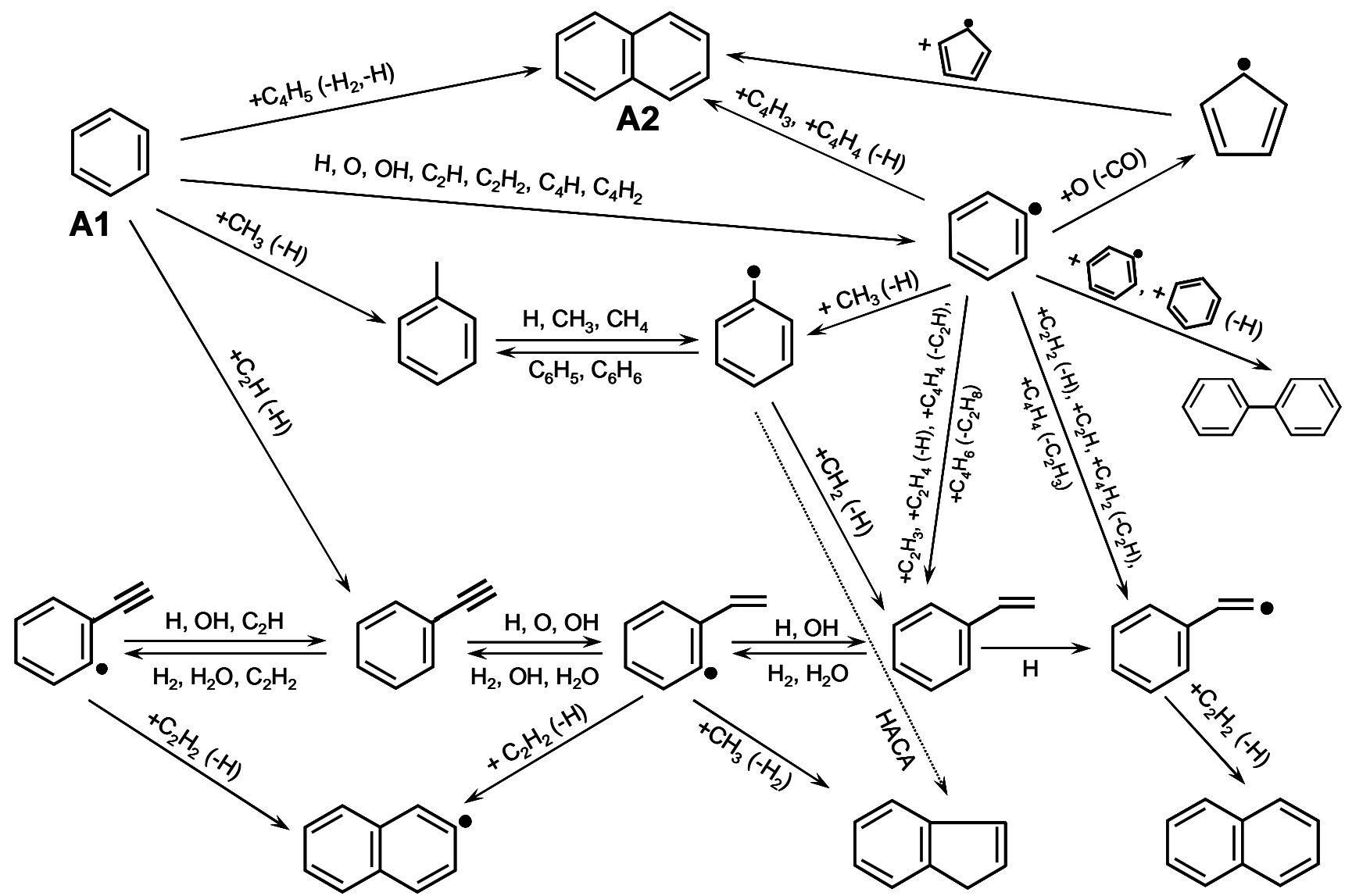

Fig. 2. Schematic representation of the aromatic growth pathways of two-ring aromatic compounds considered by the chemical kinetic mechanism of Slavinskaya and Frank [36]. 


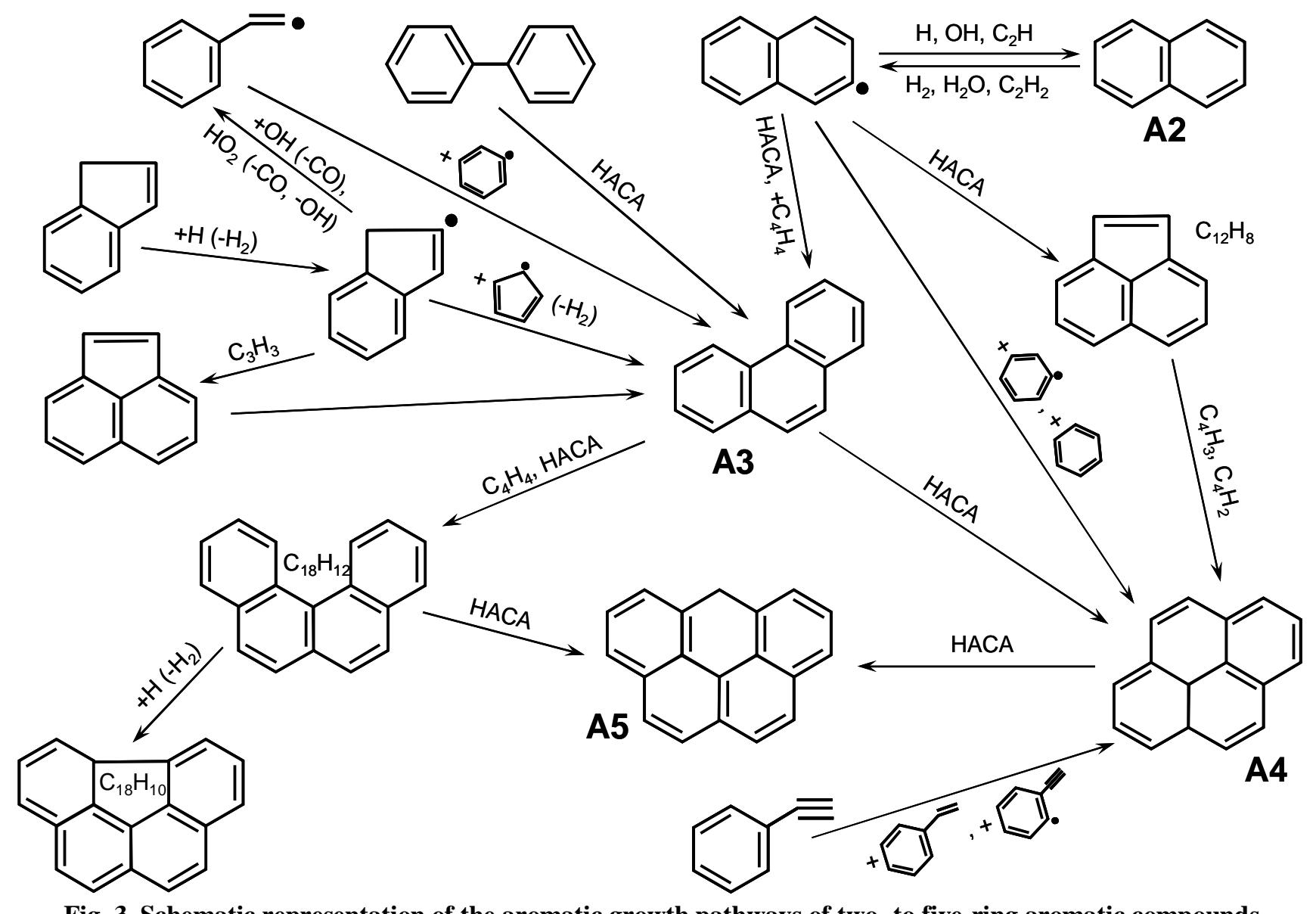

Fig. 3. Schematic representation of the aromatic growth pathways of two- to five-ring aromatic compounds considered by the chemical kinetic mechanism of Slavinskaya and Frank [36].

Updates that have been made to the mechanism since it was published in 2009 [36] are briefly described. The following upgrades have been made to take into account recent investigations and to improve the model's predictive capabilities. The principal modifications are summarized in Table 1.

First, the $\mathrm{H}_{2} / \mathrm{O}_{2}$ kinetics were revisited and adjusted. New advances [70,71,72,73,74] in $\mathrm{H}_{2} / \mathrm{O}_{2}$ chemistry have been adopted and have resulted in the replacement of rate coefficients, and in the extension of the $\mathrm{H}_{2} / \mathrm{O}_{2}$ submodel, reactions R1-R11 in Table 1 .

Further model adjustments have been made concerning the chemical kinetic and thermodynamic data for the PAH components. The thermodynamic data for cyclopentan, benzyl, and indene, which are all key species involved in PAH formation, have been updated to reflect the most recent available data. Reaction pathways, R12-R15, involving cyclopentadienyl chemistry were revised based upon a series of investigations $[75,76,77,78]$. New routes to indene formation, R16-R19, R21, and R28, involving acetylene, benzene, benzyl, phenyl, propargyl, and butadiene, have been included in the mechanism based on recent studies [78,79,80,81]. These reactions have been taken as analogous to reactions R20, and R22-R25. The thermal decomposition reactions of benzyl radical were revised taking into account experimental data obtained in [80].

Adjustments have also been made for reactions of 2- , 3-, and 4- aromatic ring molecules with $\mathrm{O}$ and $\mathrm{OH}$ radicals. For reactions R29-R31, modifications have been implemented based on Mati et al. [82]. For other ring-opening reactions of heavy aromatics with $\mathrm{O}$ and $\mathrm{OH}$ radicals, $\mathrm{R} 32-\mathrm{R} 38$, which are endothermic by approximately $40 \mathrm{kcal} / \mathrm{mol}$ relative to the reactants, the activation energy has been revised and increased with respect to the value proposed by Wang and Frenklach [83]. 
Several reactions have been prescribed as irreversible in order to reduce the numerical stiffness of the system, which was caused by unrealistic rates for reverse reactions calculated from equilibrium constants at temperatures below $1000 \mathrm{~K}$. For this reason, dissociation reactions of A4, benzo(ghi)fluoranthen, and benzo(a)pyrene, R39-R42, have been replaced with irreversible recombination reactions having rate coefficients determined by analogy to $\mathrm{A} 1=\mathrm{C}_{4} \mathrm{H}_{4}+\mathrm{C}_{2} \mathrm{H}_{2}$ from [83].

Table 1. Reactions, reaction rate parameters, and references for modified reactions, $\mathrm{pw}=$ "present work". $k=A T^{n} \exp \left(-E_{a} / T\right)$, with units of $\mathrm{mol}$, $\mathrm{s}, K$, and $\mathrm{cm}$

\begin{tabular}{|c|c|c|c|c|c|}
\hline R\# & Reaction & $A$ & $n$ & $E_{a}$ & Reference \\
\hline 1 & $\mathrm{HO}_{2}+\mathrm{HO}_{2}=\mathrm{H}_{2} \mathrm{O}_{2}+\mathrm{O}_{2}$ & $1.32 \mathrm{e} 11$ & 0.00 & -820.3 & [70] \\
\hline 2 & $\mathrm{H}_{2}+\mathrm{O}_{2}=\mathrm{OH}+\mathrm{OH}$ & $1.20 \mathrm{e} 12$ & 0.50 & 35121.0 & [71] \\
\hline 3 & $2 \mathrm{H}+\mathrm{H}_{2}=2 \mathrm{H}_{2}$ & $1.00 \mathrm{e} 17$ & -0.60 & 0.0 & [72] \\
\hline 4 & $2 \mathrm{H}+\mathrm{N}_{2}=\mathrm{H}_{2}+\mathrm{N}_{2}$ & $5.40 \mathrm{e} 18$ & -1.30 & 0.0 & {$[72]$} \\
\hline 5 & $2 \mathrm{H}+\mathrm{AR}=\mathrm{H}_{2}+\mathrm{AR}$ & $6.53 \mathrm{e} 17$ & -1.00 & 0.0 & [70] \\
\hline 6 & $2 \mathrm{H}+\mathrm{H}_{2} \mathrm{O}=\mathrm{H}_{2}+\mathrm{H}_{2} \mathrm{O}$ & $1.00 \mathrm{e} 19$ & -1.00 & 0.0 & [72] \\
\hline 7 & $\mathrm{OH}+\mathrm{H}_{2}=\mathrm{H}_{2} \mathrm{O}+\mathrm{H}$ & $1.80 \mathrm{e} 09$ & 1.20 & 2370.0 & [73] \\
\hline 8 & $\mathrm{H}+\mathrm{O}_{2}\left(+\mathrm{M} / \mathrm{Ar} / \mathrm{O}_{2}\right)=\mathrm{HO}_{2}\left(+\mathrm{M} / \mathrm{Ar} / \mathrm{O}_{2}\right)$ & $4.66 \mathrm{e} 12$ & 0.40 & 0.0 & [74] \\
\hline 9 & $\mathrm{H}+\mathrm{O}_{2}\left(+\mathrm{H}_{2} \mathrm{O}\right)=\mathrm{HO}_{2}\left(+\mathrm{H}_{2} \mathrm{O}\right)$ & $9.06 \mathrm{e} 12$ & 0.20 & 0.0 & [74] \\
\hline 10 & $\mathrm{H}+\mathrm{HO}_{2}=\mathrm{H}_{2}+\mathrm{O}_{2}$ & $2.00 \mathrm{e} 14$ & 0.00 & 1030.0 & {$[70] * 2$} \\
\hline 11 & $\mathrm{H}+\mathrm{HO}_{2}=2 \mathrm{OH}$ & $3.00 \mathrm{e} 14$ & 0.00 & 700.0 & {$[70] / 1.3$} \\
\hline 12 & $\mathrm{C}_{5} \mathrm{H}_{6}+\mathrm{C}_{2} \mathrm{H}_{3}=\mathrm{A} 1+\mathrm{CH}_{3}$ & $2.12 \mathrm{e} 67$ & -6.08 & 21320.0 & {$[75]$} \\
\hline 13 & $\mathrm{C}_{5} \mathrm{H}_{5}+\mathrm{CH}_{3}=\mathrm{A} 1+2 \mathrm{H}$ & $1.00 \mathrm{e} 18$ & 0.00 & 30000.0 & {$[76,77]$} \\
\hline 14 & $\mathrm{C}_{5} \mathrm{H}_{5}+\mathrm{H}_{2} \mathrm{CCCH}=\mathrm{A} 1 \mathrm{C}_{2} \mathrm{H}+2 \mathrm{H}$ & $3.00 \mathrm{e} 16$ & 0.00 & 29131.0 & [76] \\
\hline 15 & $\mathrm{H}_{2} \mathrm{CCCH}+\mathrm{C}_{2} \mathrm{H}_{2}=\mathrm{C}_{5} \mathrm{H}_{5}$ & $2.40 \mathrm{e} 11$ & 0.00 & 5030.0 & [78] \\
\hline 16 & $\mathrm{C}_{7} \mathrm{H}_{7}+\mathrm{C}_{2} \mathrm{H}_{2}=\mathrm{INDENE}+\mathrm{H}$ & $6.00 \mathrm{e} 11$ & 0.00 & 5030.0 & [78] \\
\hline 17 & $\mathrm{C}_{5} \mathrm{H}_{5}+\mathrm{C}_{4} \mathrm{H}_{4}=\mathrm{INDENE}+\mathrm{H}$ & $6.00 \mathrm{e} 11$ & 0.00 & 5030.0 & [78] \\
\hline 18 & $\mathrm{C}_{5} \mathrm{H}_{5}+\mathrm{C}_{4} \mathrm{H}_{2}=\mathrm{INDENYL}$ & $1.20 \mathrm{e} 12$ & 0.00 & 5030.0 & [78] \\
\hline 19 & $\mathrm{~A} 1+\mathrm{H} 2 \mathrm{CCCH} \rightarrow \mathrm{INDENE}+\mathrm{H}$ & $1.50 \mathrm{e} 14$ & 0.00 & 25912.2 & [79] \\
\hline 20 & $\mathrm{INDENE}+\mathrm{H}_{2} \mathrm{CCCH} \rightarrow \mathrm{A} 2 \mathrm{R} 5+\mathrm{H}+\mathrm{H}_{2}$ & $1.50 \mathrm{e} 14$ & 0.00 & 25912.2 & [79] \\
\hline 21 & $\mathrm{~A} 1-+\mathrm{H}_{2} \mathrm{CCCH} \rightarrow \mathrm{INDENE}$ & $3.86 \mathrm{e} 12$ & 0.00 & 6850.5 & [79] \\
\hline 22 & $\mathrm{C}_{7} \mathrm{H}_{7}+\mathrm{H}_{2} \mathrm{CCCH} \rightarrow \mathrm{A} 2+2 \mathrm{H}$ & $3.86 \mathrm{e} 12$ & 0.00 & 6850.5 & [79] \\
\hline 23 & $\mathrm{~A} 2 \mathrm{CH}_{2}+\mathrm{H}_{2} \mathrm{CCCH} \rightarrow \mathrm{A} 3+2 \mathrm{H}$ & $3.86 \mathrm{e} 12$ & 0.00 & 6850.5 & [79] \\
\hline 24 & INDENYL+H ${ }_{2} \mathrm{CCCH}=>\mathrm{P} 2$ & $4.00 \mathrm{e} 11$ & 0.00 & 7000.0 & {$[79, \mathrm{pw}]$} \\
\hline 25 & $\mathrm{INDENE}+\mathrm{H}_{2} \mathrm{CCCH}=>\mathrm{P} 2+\mathrm{H}$ & $1.54 \mathrm{e} 14$ & 0.00 & 25912.2 & {$[79, \mathrm{pw}]$} \\
\hline 26 & $\mathrm{C}_{7} \mathrm{H}_{7}=\mathrm{C}_{4} \mathrm{H}_{4}+\mathrm{H}_{2} \mathrm{CCCH}$ & $2.00 \mathrm{e} 14$ & 0.00 & 42300.0 & {$[80]$} \\
\hline 27 & $\mathrm{C}_{7} \mathrm{H}_{7}=\mathrm{C}_{5} \mathrm{H}_{5}+\mathrm{C}_{2} \mathrm{H}_{2}$ & $6.00 \mathrm{e} 13$ & 0.00 & 35000.0 & [80] \\
\hline 28 & $\mathrm{C}_{4} \mathrm{H}_{6}+\mathrm{A} 1-=\mathrm{INDENE}+\mathrm{CH}_{3}$ & $1.42 \mathrm{e} 13$ & 0.00 & 14000.0 & {$[81]$} \\
\hline 29 & $\mathrm{~A} 2+\mathrm{O}=\mathrm{A} 2-+\mathrm{OH}$ & $2.00 \mathrm{e} 13$ & 0.00 & 7400.0 & {$[82]$} \\
\hline 30 & $\mathrm{~A} 2 \mathrm{R} 5+\mathrm{O} \rightarrow \mathrm{A} 2-+\mathrm{HCCO}$ & $2.00 \mathrm{e} 13$ & 0.00 & 7400.0 & {$[82]$} \\
\hline 31 & $\mathrm{BGHIF}+\mathrm{O}=\mathrm{HCCO}+\mathrm{A} 4-$ & $2.00 \mathrm{e} 13$ & 0.00 & 7400.0 & {$[82]$} \\
\hline 32 & $\mathrm{~A} 2+\mathrm{O}=\mathrm{n}-\mathrm{C}_{8} \mathrm{H}_{7}+\mathrm{HCCO}$ & $2.00 \mathrm{e} 13$ & 0.00 & 21000.0 & {$[\mathrm{pw}]$} \\
\hline 33 & $\mathrm{~A} 2+\mathrm{O}=\mathrm{A} 1 \mathrm{C}_{2} \mathrm{H}_{3} *+\mathrm{HCCO}$ & $2.00 \mathrm{e} 13$ & 0.00 & 21000.0 & {$[\mathrm{pw}]$} \\
\hline 34 & $\mathrm{~A} 3+\mathrm{O} \rightarrow \mathrm{HCCO}+\mathrm{P} 2-$ & $2.00 \mathrm{e} 13$ & 0.00 & 21000.0 & [pw] \\
\hline 35 & $\mathrm{~A} 3+\mathrm{OH}=\mathrm{CH}_{2} \mathrm{CO}+\mathrm{P} 2-$ & $4.00 \mathrm{e} 13$ & 0.00 & 16000.0 & [pw] \\
\hline 36 & $\mathrm{~A} 4+\mathrm{O}=\mathrm{A} 3-+\mathrm{HCCO}$ & $2.00 \mathrm{e} 13$ & 0.00 & 21000.0 & [pw] \\
\hline 37 & $\mathrm{~A} 4+\mathrm{OH}=\mathrm{A} 3-+\mathrm{CH}_{2} \mathrm{CO}$ & $2.00 \mathrm{e} 13$ & 0.00 & 21000.0 & [pw] \\
\hline 38 & $\mathrm{BAPYR}+\mathrm{O}=\mathrm{HCCO}+\mathrm{C}_{18} \mathrm{H}_{11}$ & $2.00 \mathrm{e} 13$ & 0.00 & 21000.0 & {$[\mathrm{pw}]$} \\
\hline
\end{tabular}




\begin{tabular}{|l|l|l|l|l|l|}
\hline 39 & $\mathrm{C} 4 \mathrm{H} 2+\mathrm{A} 2 \mathrm{R} 5 \rightarrow \mathrm{A} 4$ & $6.00 \mathrm{e} 02$ & 2.23 & -569.2 & {$[83, \mathrm{pw}]$} \\
40 & $\mathrm{~A} 2 \mathrm{R} 5+\mathrm{C} 6 \mathrm{H} 2 \rightarrow \mathrm{BGHIF}$ & $6.00 \mathrm{e} 02$ & 2.23 & -569.2 & {$[83, \mathrm{pw}]$} \\
41 & $\mathrm{~A} 2+\mathrm{C} 8 \mathrm{H} 2 \rightarrow \mathrm{BGHIF}$ & $6.00 \mathrm{e} 02$ & 2.23 & -569.2 & {$[83, \mathrm{pw}]$} \\
42 & $\mathrm{C} 4 \mathrm{H} 2+\mathrm{A} 4 \rightarrow \mathrm{BAPYR}$ & $6.00 \mathrm{e} 02$ & 2.23 & -569.2 & {$[83, \mathrm{pw}]$} \\
\hline
\end{tabular}

\section{Numerical methods}

\subsection{Numerical Solution}

The governing equations and boundary conditions are solved over a two-dimensional mesh that extends $12.29 \mathrm{~cm}$ in the axial direction and $4.75 \mathrm{~cm}$ in the radial direction, and is divided into $192 \mathrm{z} z) \times$ 88 ( $r$ ) control volumes. A non-uniform mesh is used to save computational cost while still resolving large spatial gradients. The grid is finest in the flame region with maximum resolutions of $0.02 \mathrm{~cm}$ between $r=0.0 \mathrm{~cm}$ and $r=0.95 \mathrm{~cm}$ in the radial direction, and $0.05 \mathrm{~cm}$ between $z=0.0 \mathrm{~cm}$ and $z=$ $6.675 \mathrm{~cm}$ in the axial direction. Flat velocity profiles are assumed for the inlet fuel and oxidizer streams with values of $3.98 \mathrm{~cm} / \mathrm{s}$ and $8.9 \mathrm{~cm} / \mathrm{s}$ respectively. In order to account for preheating of the fuel mixture, the inlet temperature for fuel stream is set to $400 \mathrm{~K}$. This value has been set based on an iterative trial and error process in which the computed temperature just downstream of the fuel tube exit was matched to experimental data in [54]. The oxidizer stream temperature is set to $300 \mathrm{~K}$. Symmetry, free-slip, and zero-gradient conditions are enforced at the centerline, the outer radial boundary, and the outflow boundary, respectively.

As in previous works $[28,29,31]$, finite volume discretizations are used to linearize the differential terms in the governing equations across each control volume. A staggered mesh is used to handle the pressure and velocity coupling and a semi-implicit scheme is used to solve the discretized equations at each discrete time interval. The diffusive terms are discretized using a second-order central difference scheme while the convective terms are discretized using a power law scheme [84]. The thermal properties of the gaseous species and chemical reaction rates are obtained using CHEMKIN subroutines $[85,86]$. Transport properties which include mixture-averaged quantities for viscosities, conductivities, and diffusion coefficients, as well as thermal diffusion coefficients for $\mathrm{H}$ and $\mathrm{H}_{2}$, are evaluated using TPLIB $[87,88]$.

Pseudo-transient continuation is used to aid convergence from an arbitrary starting estimate. At each pseudo-time step, after the momentum and pressure correction equations are solved globally, the gaseous species equations are solved in a coupled manner at each control volume to effectively deal with the stiffness of the system and speedup the convergence process (i.e., a linear system coupling each of the species mass conservation equations is formed and solved at each control volume). After iteration of the species equations, the sectional transport equations are also solved simultaneously in a similar fashion. The energy equation is then solved to generate an updated global temperature field and a convergence check is performed. If the vector norms of the independent variables change by less than one one-thousandth of their value from one timestep to the next, then the algorithm is deemed to have converged. Otherwise iteration proceeds, again starting with solution of the momentum and pressure correction equations. Care was taken to ensure that the computed solution was independent of the convergence tolerance used, by lowering the convergence tolerance by an order of magnitude and checking for changes in the solution.

\subsection{Parallel implementation}

Due to the high computational intensity of the problem, solution is sought using parallel processing. Distributed-memory parallelization with strip-domain decomposition is employed. The 
computational domain is divided uniformly into 192 subdomains with the boundaries of each subdomain perpendicular to the $z$-axis. Therefore, each processing unit is responsible for a single row of 88 control volumes in the radial direction. The algorithm uses the Fortran Message Passing Interface library $[33,34]$ to handle interprocess communication. The computations are performed on the General Purpose Cluster (GPC) of SciNet, on twelve 16-core Intel Xeon E5540s with $2.53 \mathrm{GHz}$ chip speeds and InfiniBand network interconnect. Each iteration takes approximately 3.5 to 5.8 seconds (depending on the number of chemical species being tracked), and approximately 25000 to 35000 iterations are required for the solution to converge from an arbitrary starting estimate.

This choice of semi-implicit time marching scheme lends itself particularly well to parallelization and to accommodating large chemical kinetic mechanisms. At each control volume at any given timestep, the algorithm solves $N$ governing equations for species mass conservation (where $N=93,101$, or 155 depending on the mechanism being used), 70 governing equations for particle dynamics, and 4 governing equations for the thermophysical variables (temperature, pressure, and two velocity components). As a result, the ratio of governing equations solved in an implicit coupled fashion at each control volume (species and particle dynamics) to governing equations that are solved globally (temperature, pressure, and velocity) is high (at least 163:4 in the present study) and will only increase if larger chemical kinetic mechanisms are used. Since solution of the species and particle dynamics equations at any particular control volume requires information from the previous timestep only, it can be parallelized in a straight-forward manner up to a limit of one control volume per process. A single master process collects the species and particle dynamics information and performs an update to the energy, momentum, and pressure correction equations. Scaling tests were performed using 93 and 155 species and the results are summarized in Table 2.

Table 2. Parallel scaling study using 93 and 155 chemical species (167 and 229 variables per control volume, respectively).

\begin{tabular}{|c|c|c|c|c|}
\hline \multirow{2}{*}{$\begin{array}{c}\text { Number of } \\
\text { Cores }\end{array}$} & \multicolumn{2}{|c|}{ Time per timestep (s) } & \multicolumn{2}{c|}{ Parallel Efficiency } \\
93 species & 155 species & 93 species & 155 species \\
\hline 1 & 353.0 & 603.9 & 1.0 & 1.0 \\
\hline 4 & 90.7 & 155.2 & 0.97 & 0.97 \\
\hline 16 & 23.9 & 39.5 & 0.93 & 0.96 \\
\hline 32 & 12.8 & 21.3 & 0.86 & 0.89 \\
\hline 64 & 7.23 & 12.0 & 0.76 & 0.79 \\
\hline 96 & 5.35 & 8.84 & 0.69 & 0.71 \\
\hline 192 & 3.53 & 5.80 & 0.52 & 0.54 \\
\hline
\end{tabular}

For both data sets (93 and 155 species), increasing the number of cores from 1 to 192 effectively reduces compute time by a factor of $\sim 100$. In practical terms, with the computer hardware available, this translates to compute time being reduced from many months to just a few days (accounting for human input and resource sharing factors). For both data sets, the parallel efficiency, which is the ratio of resources used in serial $(353.0 \mathrm{~s}$ for 93 species and $603.9 \mathrm{~s}$ for 155 species) to resources used in parallel (Number of cores $\times$ Time per iteration) decreases roughly linearly as a function of the number of cores used. This highlights the unfortunate trade-off between computing efficiency and compute time in these particular cases. However, parallel efficiency increases with increasing chemical mechanism size since linear system formation and solution is known to scale with the square of the number of equations to be solved, and interprocess communication scales linearly with the number of species. Therefore, increasing the number of chemical species increases the ratio of work being done by each core without the need for network communication, to time spent by each core in network communication. It can be seen from Fig. 4 that parallel scaling is more efficient with the 
larger chemical mechanism size (the best fit line for 155 species has a lesser slope than that for 93 species). This result is promising for the prospect of moving to even larger chemical mechanisms, such as those required to simulate jet fuel combustion (see our recent results in [31]), or to incorporate further detail in the PAH growth mechanism, since they suggest that the number of cores to which the algorithm will effectively scale will increase with increasing mechanism size.

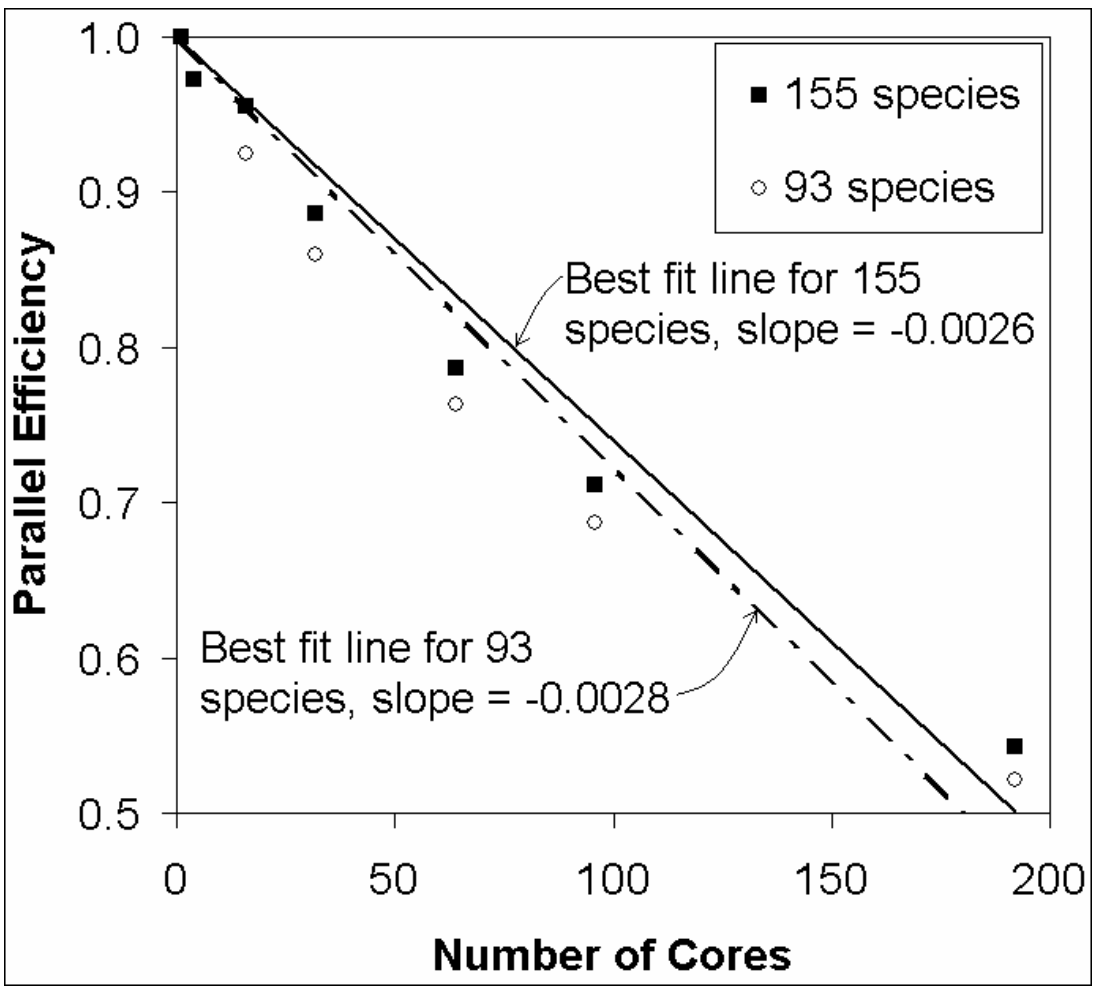

Fig. 4. Parallel scaling efficiency as a function of the number of cores for 93 and 155 species in a coflow ethylene/air diffusion flame.

\section{Results and discussion}

\subsection{Soot volume fraction as a function of active surface sites}

Computations are performed for the three mechanisms described in Section 2.3, each for a range of values of $\alpha$, the fraction of soot surface sites available for chemical reaction. Consistent with the procedure in [11], the theoretical maximum active surface site density, $\chi$, is imposed as $2.3 \times 10^{15}$ $\mathrm{cm}^{-2}$, and $\alpha$ is permitted to vary between 0 and 1 . Therefore, the number of soot surface sites available for chemical reaction is the product of $\chi$ and $\alpha$. In the present study, as was done in [11], $\alpha$ is determined by matching the experimental and measured maximum soot volume fraction. The authors note that this procedure may be likely to result in fortuitous cancellation, whereby $\alpha$ is either over- or underestimated, making up for either deficiencies or excesses in soot formation by other processes. For this reason, the flame in the present study is particularly useful in assessing the accuracy of the soot model, in that it contains two distinct soot formation regimes; the rich low-temperature inceptiondominated central region of the flame, where it is expected that soot concentrations will be insensitive to $\alpha$, and the high-temperature diffusion zone along the wings, where high sensitivity to $\alpha$ is expected. As will be demonstrated below, the present study seeks a value or expression for $\alpha$, with which the soot model can correctly predict soot formation in both of these regions. 
Although it is believed that $\alpha$ should be dependent on local conditions such as temperature, those dependencies, and in fact the actual ranges of $\alpha$, are poorly known, as outlined in Section 1 . For this reason, in the present study $\alpha$ will be considered to be a constant, independent of local conditions. Six different values of $\alpha$ are tested with the present chemical mechanism, adapted from Slavinskaya and Frank [36]. The results for global maximum soot volume fraction, $f_{v}$, (which occurs on the wings) and maximum soot volume fraction along the centerline, as functions of $\alpha$ are plotted in Fig. 5.a. Maximum soot volume fraction exhibits a high dependence on $\alpha$, indicating that it is dominated by surface growth, varying linearly from $3.3 \mathrm{ppm}$ at $\alpha=0.03$ to $13.9 \mathrm{ppm}$ at $\alpha=0.12$. The maximum soot volume fraction was measured to be approximately $9.5 \mathrm{ppm}$ [53], which is achieved in the model using $\alpha=0.078$. The maximum soot volume fraction along the centerline is insensitive to $\alpha$, indicating that it is dominated by other processes - primarily inception, varying from $0.91 \mathrm{ppm}$ to $1.17 \mathrm{ppm}$ for the range of $\alpha$ studied here. 


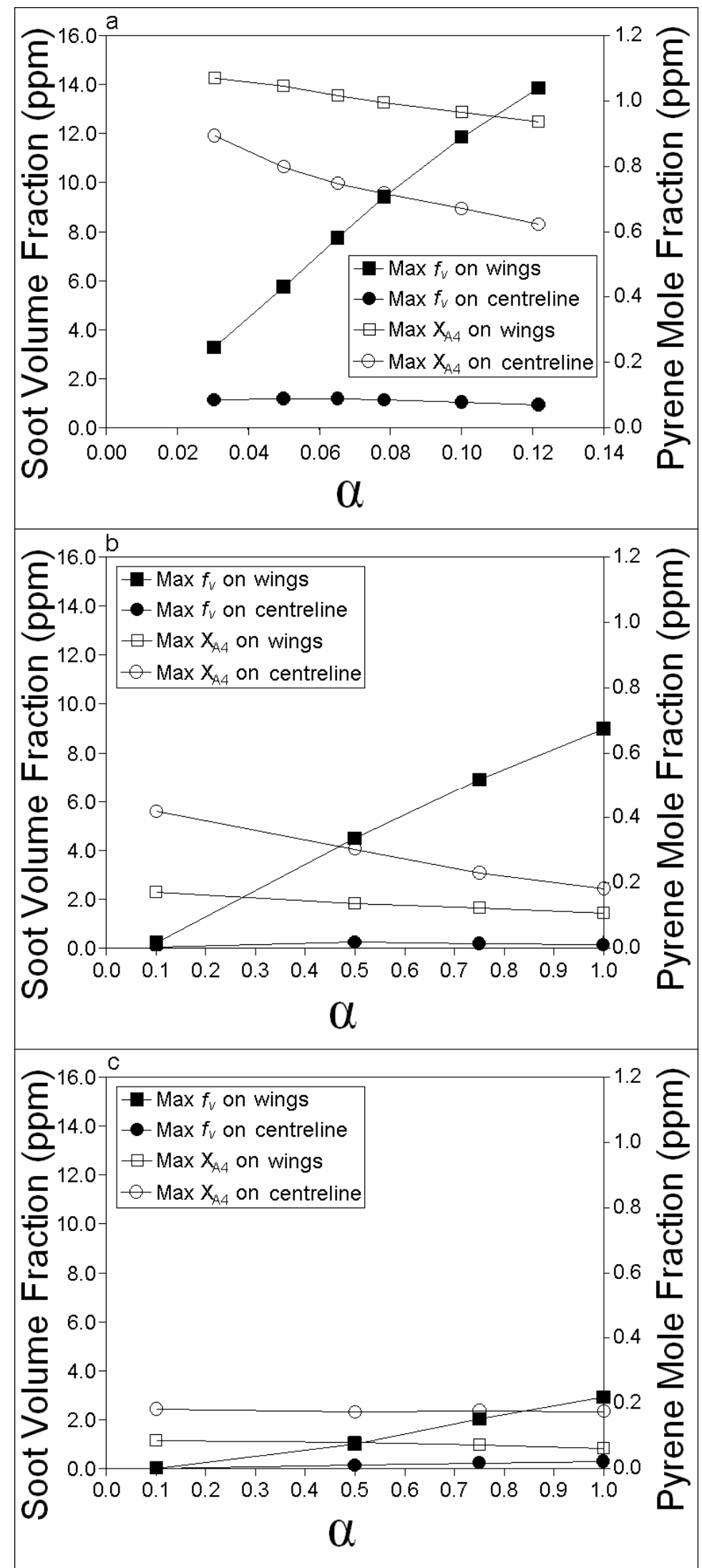

Fig. 5. Maximum soot volume fraction and pyrene mole fraction on the wings of the flame, and maximum soot volume fraction and pyrene mole fraction along the centerline, as functions of $\alpha$, using the chemical kinetic mechanism of a) the present work b) Appel et al. [11], and c) Marinov et al. [38]. 
Global maximum soot volume fraction and maximum centerline soot volume fraction as functions of $\alpha$, computed using the mechanisms of Appel et al. [11] and Marinov et al. [38], are plotted in Fig. 5.b and c, respectively. It can be seen that much larger values of $\alpha$ need to be used with these two mechanisms to achieve soot volume fractions in the 1-10 ppm range, than were needed with the present mechanism. Again, peak soot volume fraction can be seen to increase linearly with increasing $\alpha$ with these two mechanisms, indicating the dominance of surface growth when these models are used. Using a maximum theoretical value of $\alpha=1.0$, the model utilizing the mechanism of Appel et al. predicts a peak soot volume fraction of $9.0 \mathrm{ppm}$, which is close to the experimentally determined value of $9.5 \mathrm{ppm}$ [53]. However, a value of $\alpha=1.0$ is likely to be unrealistically high, since surface site availability is known to decrease at high temperatures [32]. Therefore, the model of Appel et al. relies too heavily on surface growth for soot formation. This is confirmed by considering the maximum centerline soot volume fraction predicted with the Appel et al. mechanism in Fig. 5.b. Here, the predicted soot concentrations are also independent of $\alpha$, but they are an order of magnitude lower than those predicted with the present mechanism (Fig. 5a). Since soot formation in this area of the flame is known to be inception-dominated, the over-reliance of soot formation on surface growth with the Appel et al. mechanism becomes problematic.

The flame model fails to predict physically realistic peak soot concentrations when the mechanism of Marinov et al. is used. Maximum peak soot volume fraction was computed to be only $2.9 \mathrm{ppm}$ with $\alpha=1.0$. For this reason, only the data sets computed with the present mechanism (at $\alpha=$ 0.078) and with the mechanism of Appel et al. (at $\alpha=1.0$ ) are compared in detail in the following sections. It is also worth noting that the maximum centerline soot volume fractions are considerably lower with the mechanisms of Appel et al. and Marinov et al. for all values of $\alpha$. An explanation for these trends can be obtained from looking at pyrene concentrations, the largest PAH common to all three mechanisms.

Also plotted in Fig. 5 are the maximum pyrene (A4) mole fractions occurring on the wings, and maximum pyrene mole fraction along the centerline, as functions of $\alpha$. Pyrene mole fraction can be seen to vary weakly, decreasing monotonically with $\alpha$. The reason for the decrease is that as $\alpha$ increases, consumption of acetylene via surface addition also increases. As acetylene is a primary precursor to PAHs, this leads to a decrease in pyrene mole fraction. The reduction in pyrene concentration with increasing $\alpha$ would suggest that particle inception rates along the centreline and wings are also decreasing slightly.

The high value of $\alpha$ that must be used with the mechanism of Appel et al. is likely an artifact of the PAH chemistry, as pyrene concentrations are ten times lower along the wings than with the present mechanism. This further suggests that only through unphysical augmentation of surface growth, counteracting deficiencies in PAH formation, can physically accurate peak soot concentrations be achieved with the mechanism of Appel et al.

The centerline pyrene concentrations are consistently predicted two to three times higher with the present mechanism, as compared to the other two mechanisms. The increase in the centerline pyrene concentrations led to enhanced soot inception in the central region of the flame computed with the present mechanism. The enhanced inception results in centerline soot concentrations being an order of magnitude higher than with the other two mechanisms (see Fig. 5). Furthermore, the present mechanism predicts peak pyrene mole fractions to be located on the wings of the flame, whereas with the other two mechanisms, pyrene mole fractions peak on the centerline for all values of $\alpha$. These key differences are consistent with the variations between the PAH growth reactions of the three mechanisms. For example, propargyl recombination to form benzene is made irreversible in Appel et al., which can lead to low concentrations of propargyl and other related $\mathrm{C}_{3}$ species on the downstream side of the main reaction zone, inhibiting further PAH growth. PAH growth from benzene to pyrene in 
both Appel et al. and Marinov et al. are described primarily by the interactions of aromatics with small species $\left(\mathrm{C}_{4}\right.$ or smaller), which get consumed early in the reaction zone and cause PAH growth to stall. By contrast, the present mechanism considers more formation routes for large PAHs, including numerous aromatic combination pathways that remain active at high temperatures.

Temperature and soot volume fraction contours are depicted for the present mechanism data on the left and right panels of Fig. 6, respectively. Two distinct hot regions can be seen in the flame (left panel of Fig. 6), one along the wings near $r=0.5 \mathrm{~cm}$, spanning from $z=0.0 \mathrm{~cm}$ to $z=4.0 \mathrm{~cm}$, and one in the centre of the flame, spanning from $z=6.5 \mathrm{~cm}$ to $z=7.5 \mathrm{~cm}$. Soot is primarily formed along the wings of the flame (right panel of Fig. 6), with the highest concentrations occurring near $r=0.5 \mathrm{~cm}$, spanning from $z=2.5 \mathrm{~cm}$ to $z=4.5 \mathrm{~cm}$. The maximum flame temperature is computed as $2092 \mathrm{~K}$, and the maximum soot volume fraction is predicted as $9.4 \mathrm{ppm}$. For the Appel et al. mechanism (temperature and soot volume fraction contours not shown), when $\alpha=1.0$ is imposed such that the maximum soot volume fraction is $9.0 \mathrm{ppm}$, the maximum flame temperature is computed as $2047 \mathrm{~K}$, and similarly, for the Marinov et al. mechanism (temperature and soot volume fraction contours not shown), when $\alpha=1.0$ is imposed such that the maximum soot volume fraction is $2.9 \mathrm{ppm}$, the maximum flame temperature is computed as $2076 \mathrm{~K}$. In all three cases, the overall shape and structure of the flame contours were similar.
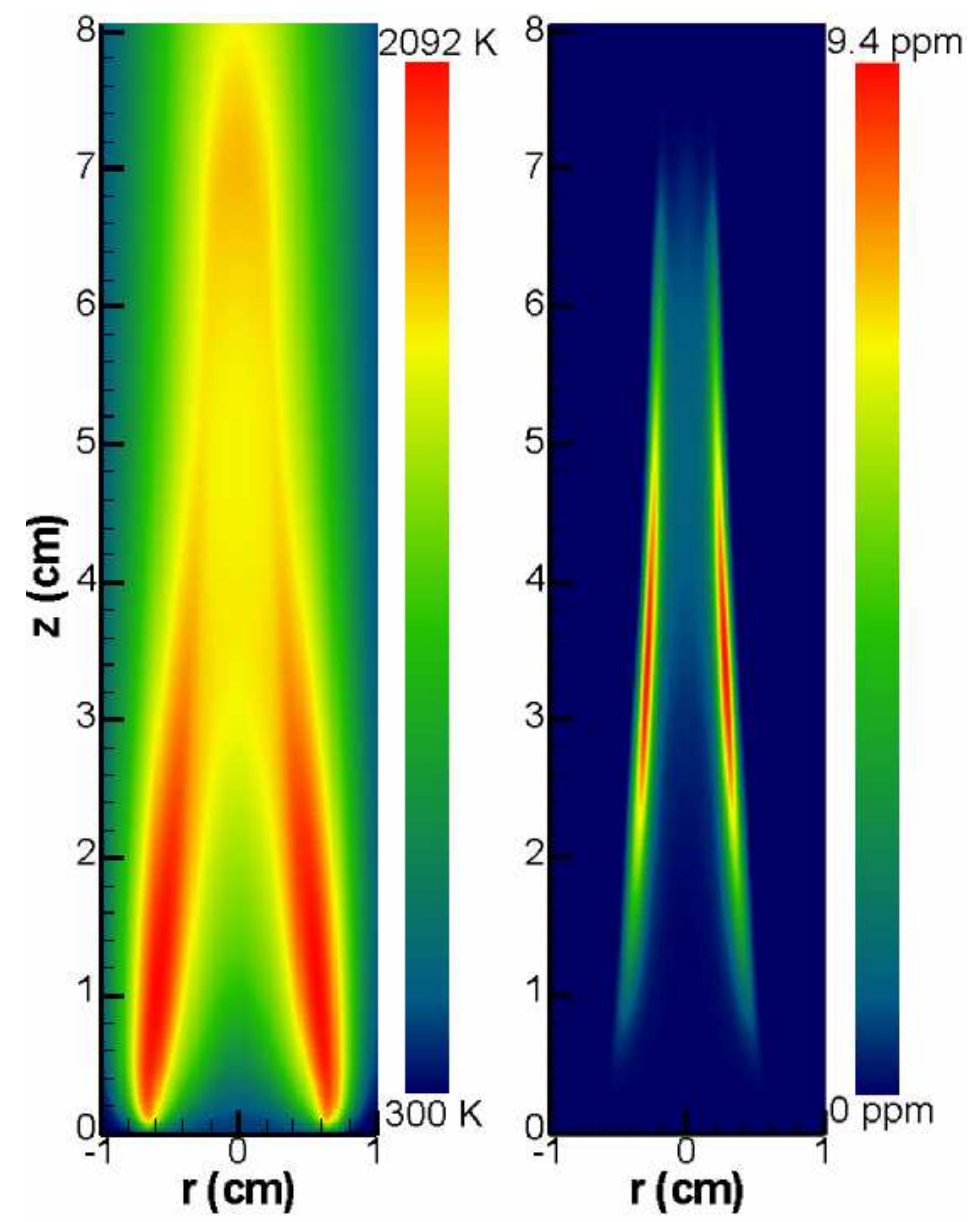

Fig. 6. Computed isotherms (left panel) and computed isopleths of soot volume fraction (right panel) of the coflow ethylene/air diffusion flame computed with the present chemical kinetic mechanism at $\alpha=0.078$. (Image intended for reproduction in color, both online and in print.) 


\subsection{Comparisons to experimental data}

The data generated from the simulations with the present mechanism at $\alpha=0.078$, and with the mechanisms of Appel et al. at $\alpha=1.0$ are compared in further detail. Temperature profiles generated with the two mechanism are compared to experimental data from [50] at two different axial heights, $z=$ $2 \mathrm{~cm}$ and $z=7 \mathrm{~cm}$ in Fig. 7.a. These heights were chosen for comparison in part due to the availability of experimental data and partly because they represent two distinct temperature regimes, off-centerline peaking at $z=2 \mathrm{~cm}$ and on-centerline peaking at $z=7 \mathrm{~cm}$. The temperature profiles predicted by the two mechanisms are nearly coincident, and reproduce the experimental data very well. The overall shape and trends of the curves are captured with the models slightly overpredicting temperature between $r=0.0 \mathrm{~cm}$ and $r=0.4 \mathrm{~cm}$, and slightly underpredicting temperature beyond $r=0.4 \mathrm{~cm}$.

Fig. 7.b compares the acetylene profiles generated by the two mechanisms to experimental data from [54] at $z=2 \mathrm{~cm}$. Again, the overall shape, trend, and magnitude of the experimental data are well reproduced by the model. Acetylene concentrations predicted with the mechanism of Appel et al. slightly underpredict the experimental data near the centreline, while both mechanisms underpredict the measured data between $r=0.3 \mathrm{~cm}$ and $r=0.5 \mathrm{~cm}$.
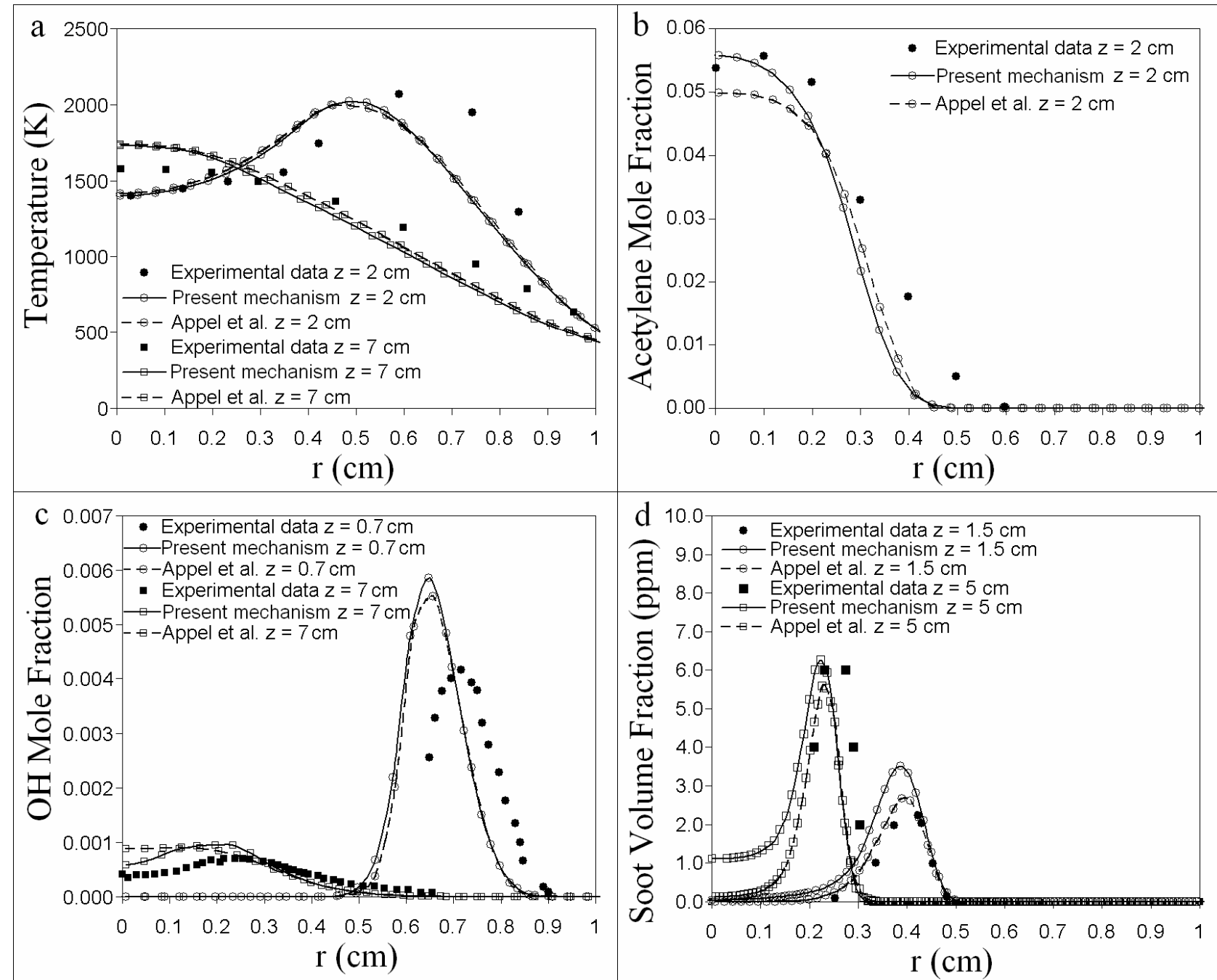

Fig. 7. Comparison of numerical predictions (present mechanism and Appel et al.) and experimental data for a) Temperature (measurements from [48]), b) Acetylene mole fraction (measurements from [52]), c) OH mole fraction (measurements from [48]), and d) Soot volume fraction (measurements from [50]) at the axial heights indicated as functions of radial distance from the centreline. 
Predicted and measured $\mathrm{OH}$ mole fractions profiles are shown in Fig. 7.c. Computed data at $z=$ $0.7 \mathrm{~cm}$ and $z=7 \mathrm{~cm}$ are compared to the measurements of [50]. Both mechanisms can reproduce the experimental data at $z=0.7 \mathrm{~cm}$ but overpredict the $\mathrm{OH}$ mole fraction at $z=7 \mathrm{~cm}$ by $30-44 \%$. The numerically predicted profile is also shifted toward the flame centreline by about $0.08 \mathrm{~cm}$.

Consistent with the comparisons made in [29], soot volume fraction radial profiles at two different axial heights, $z=1.5 \mathrm{~cm}$ and $z=5.0 \mathrm{~cm}$, are plotted in Fig. 7.d. These two heights are representative of high- and low-sooting regions of the flame. The numerical data computed using the mechanisms of the present work and Appel et al., are compared to the experimental data from [50]. At $z=1.5 \mathrm{~cm}$, measured soot volume fraction peaks just above $2.0 \mathrm{ppm}$ at a radial distance of approximately $0.4 \mathrm{~cm}$ away from the centreline. Similarly, at $z=5.0 \mathrm{~cm}$, measured soot volume fraction peaks near $6.0 \mathrm{ppm}$ at a radial distance of approximately $0.28 \mathrm{~cm}$ away from the centreline. It can be seen that using the method of determination of $\alpha$ described above, both mechanisms are capable of reproducing the shape and magnitude of the experimental data for the soot volume fraction radial profiles, with slight variations in peak value and location. At $z=5.0 \mathrm{~cm}$ (Fig. 7.d), soot volume fraction between $r=0.0$ and $r=0.1 \mathrm{~cm}$, as predicted with the present mechanism is much higher than that predicted with the mechanism of Appel et al. This discrepancy is magnified in Fig. 8, which plots experimental data from [56] and numerical centreline soot volume fraction profiles for both mechanisms on a logarithmic scale. It can be seen that only the computations performed with the present mechanism are capable of reproducing the correct order of magnitude of soot volume fraction along the centreline. The maximum soot volume fraction predicted with the mechanism of Appel et al. is one to two orders of magnitude lower than both the experimental data, and the data computed with the present mechanism. Although some underprediction still exists, centreline soot volume fraction profiles predicted with the present mechanism are within a factor of three of the experimental data. Predicting the correct order of magnitude is the key feature of this graph as there is considerable variation between experimental datasets that make use of different measurement techniques [56], and it marks an improvement over the mechanism of Appel et al. In addition, the general shape and trends of the curve are well reproduced with the present mechanism.

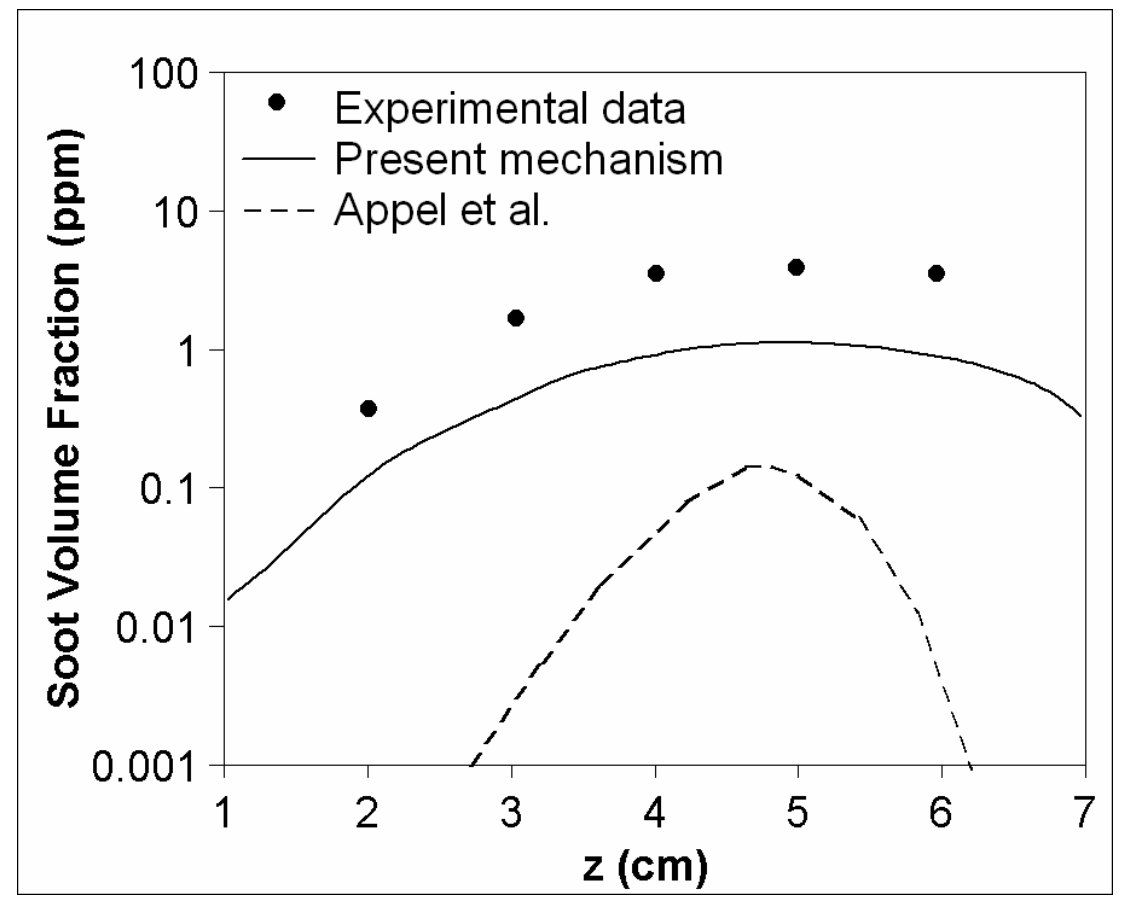

Fig. 8. Comparison of numerical (present mechanism and Appel et al.) and experimental (from [54]) soot volume fraction, along the centerline of the flame, as a function of axial height. 
To understand the differences in performance of the mechanisms along the centreline, temperature and key species involved in soot formation are plotted in Fig. 9. The temperature profiles along the centerline as predicted by both mechanisms are quite close to the experimental data from [56] (see Fig. 9.a). Between $z=3 \mathrm{~cm}$ and $z=8 \mathrm{~cm}$, the temperature predicted with the mechanism of Appel et al. is consistently $80-90^{\circ}$ higher than that of the present mechanism This discrepancy is likely due to the larger soot concentrations predicted with the present mechanism and the associated radiative cooling in this region.

Centerline profiles of acetylene, benzene, and pyrene are shown in Fig. 9.b. While the two acetylene profiles are nearly coincident, the benzene and pyrene concentrations are about a factor of four larger with the present mechanism. In addition, the aromatics profiles are much broader, exhibiting considerable concentrations for a larger span of the centerline axis than with the mechanism of Appel et al. For example, with the present mechanism, the pyrene mole fraction reaches $0.01\left(\times 10^{-5}\right)$ at a height of approximately $0.5 \mathrm{~cm}$, whereas with Appel et al, the pyrene mole fraction does not reach $0.01\left(\times 10^{-}\right.$ ${ }^{5}$ ) until a height of approximately $2.5 \mathrm{~cm}$.

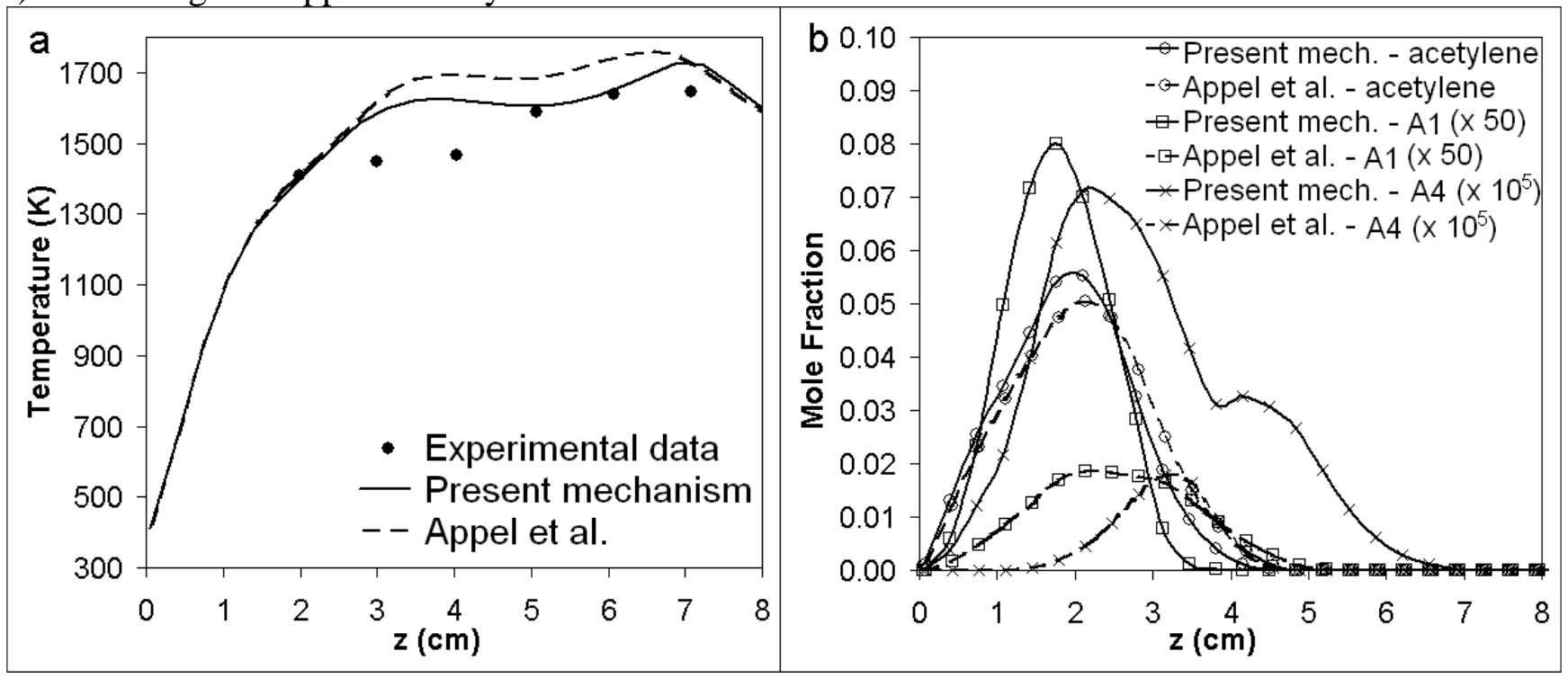

Fig. 9. Comparison of a) numerical (present mechanism and Appel et al.) and experimental (from [54]) temperature, and b) numerical (present mechanism and Appel et al.) species mole fractions along the centerline of the flame, as a function of axial height.

From Fig. 9 it can be seen that the active formation of small aromatic molecules occurs in the first stage of the main reaction zone (from $z=0.5 \mathrm{~cm}$ to $z=1.5 \mathrm{~cm}$ ) and is followed by pyrene formation (from $z=1 \mathrm{~cm}$ to $z=2.5 \mathrm{~cm}$ ). Subsequently, (from $z=2 \mathrm{~cm}$ to $z=4 \mathrm{~cm}$ ), temperature stabilizes and smaller molecules are consumed during the formation of larger aromatics (larger than pyrene). The secondary peak in pyrene concentration with the present mechanism at $z=4.5 \mathrm{~cm}$ relates to the presence of larger PAHs in the mechanism. These PAHs are formed in the region from $z=2 \mathrm{~cm}$ to $z=4 \mathrm{~cm}$ and then begin to undergo oxidation and high temperature decomposition. As pyrene is a product of their destruction, there is a slight increase in pyrene concentrations, which is followed by steady pyrene consumption after $z=4.5 \mathrm{~cm}$.

A fluid parcel entering the domain along the centerline and traversing upward, would experience essentially the same temperature and acetylene concentrations, but would experience vastly greater and more prolonged aromatic concentrations with the present mechanism. The result is that particle inception would be activated for a longer period of time (or in other words, a longer component of the path of the fluid parcel) than with the mechanism of Appel et al., and would be of greater 
magnitude. Consequently, soot formation in this inception dominated region is significantly higher with the present mechanism, leading to soot concentrations in line with those determined experimentally.

To further validate the model, comparisons of soot volume fraction and soot structure along the pathline of maximum soot can be made with experimental data in the literature [50,52,53,58]. As defined in [51], data along the pathline of maximum soot is compiled at the radial locations where soot volume fraction peaks, at discrete axial heights. The numerical data in Fig. 10 is computed using the present mechanism. Fig. 10.a shows that the simulations are able to reproduce the correct values of soot volume fraction along the pathline. This is not surprising since the parameter $\alpha$ was adjusted until the model could correctly reproduce the maximum soot volume fraction in the flame. However, the shape of the curve and overall trend are also well reproduced. Fig. 10.b and c yield more information on whether or not the model can correctly predict the structure of the soot particles. The model can reproduce the particle number density with high accuracy (Fig. 10.b) and the average primary particle diameter within a factor of two (Fig. 10.c).

To determine aggregate structure, the average number of primary particles per aggregate is plotted in Fig. 10.d. The model can reproduce the experimental trends extremely well, indicating that the coagulation/fragmentation model is of high fidelity. These results are very promising, since the model, when used with the present mechanism can correctly model soot formation along two different radial profiles (Fig. 10), the centerline of the flame (Fig. 10), and the pathline of maximum soot (Fig. 10.a), and can also correctly predict number density and particle structure (Fig. 10.b, c, and d), 


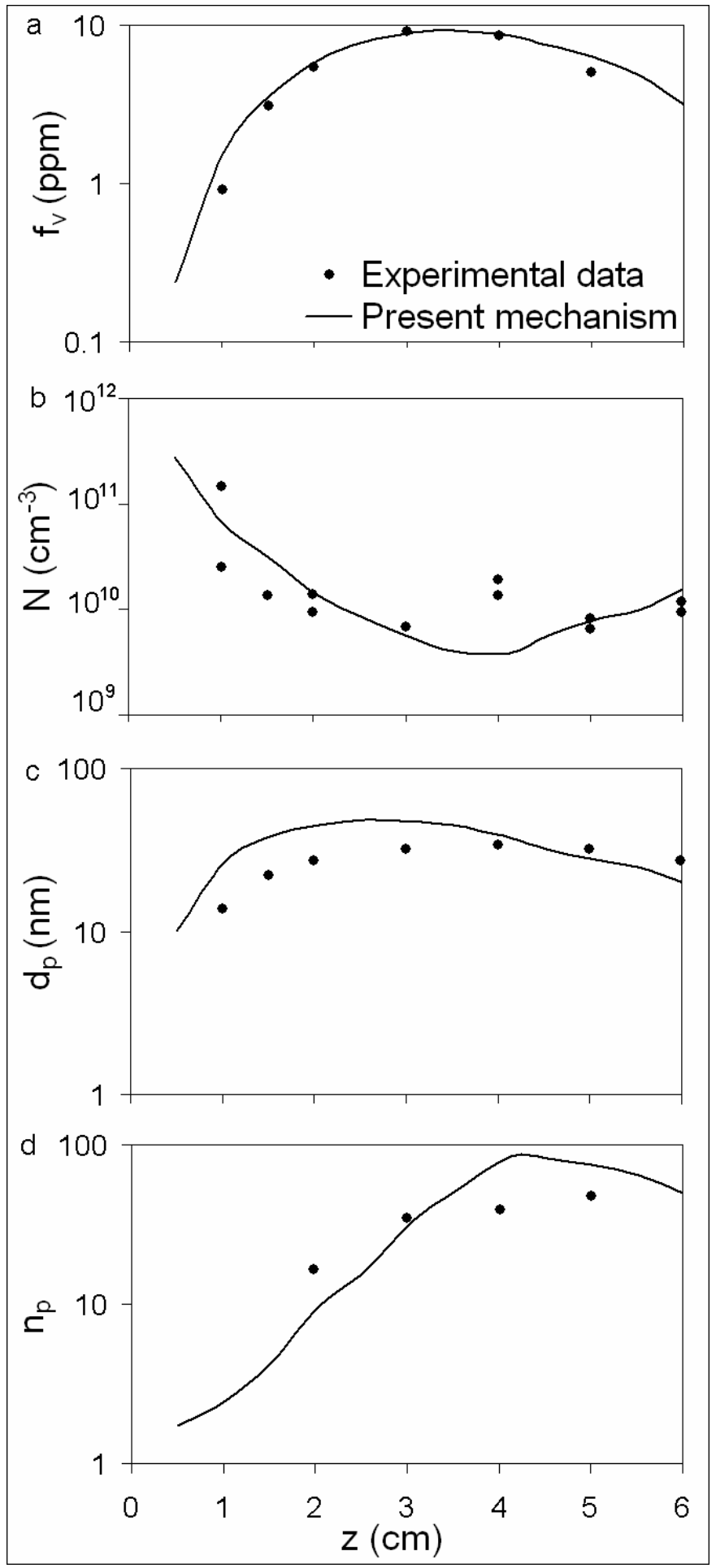

Fig. 10. Comparison of numerical (present mechanism) and experimental a) soot volume fraction, b) particle number density, c) average primary particle diameter, and d) average number of primary particles per aggregate, along the annular pathline exhibiting the maximum soot volume fraction. Measurements are from [53] for (a), [50] for (b), [52] for (c), and [58] for (d).

\section{Summary and Conclusions}

Three chemical kinetic mechanisms for $\mathrm{C}_{2}$ fuel combustion and $\mathrm{PAH}$ growth have been combined and tested with a parallelized coflow diffusion flame solver for an ethylene/air flame. The 
model contains a highly detailed particle dynamics sectional model for soot formation, which tracks aggregate size and structure. Two commonly used mechanisms from the literature, those of Appel et al. [11], and Marinov et al. [38], which model PAH growth primarily via HACA growth, were tested and compared to a recent and more comprehensive mechanism by the coauthors and their collaborators [36,37]. In each case, the mechanism that was tested was linked to the particle dynamics model via PAH based inception, surface growth, PAH condensation, oxidation, and gas phase scrubbing of consumed molecules. The mechanism was also linked to the energy equation via an optically thick gas phase radiation model that was computed in situ, and chemical heat release/absorption. In addition to the chemical processes, particle coagulation and fragmentation led to changes in the size and structure of soot particles, which were tracked using thirty-five discrete sections

With each of the three gas phase mechanisms, the optimal value of $\alpha$ was sought by fitting maximum soot volume fraction to experimental data. No value of $\alpha$ could be found using the mechanism of Marinov et al. [38]. Using the mechanism of Appel et al. [11], a maximum soot volume fraction of $9.0 \mathrm{ppm}$, which was close to the experimentally determined value of $9.5 \mathrm{ppm}$ was found with $\alpha=1.0$. When the present mechanism is employed, a maximum soot volume fraction of approximately $9.5 \mathrm{ppm}$ was achieved in the model using $\alpha=0.078$. The computed results with Appel et al. and with the present mechanism were then compared in more detail.

It was found that both sets of results could reproduce radial profiles well for temperature, acetylene mole fraction, $\mathrm{OH}$ mole fraction, and soot volume fraction when compared to experimental data in the literature, but only the results with the present mechanism could also reproduce the correct order of magnitude of soot volume fraction along the flame centerline. By comparing centerline temperature and species distributions, the differences along the centerline were attributed to the enhanced aromatic formation associated with the present mechanism. Further comparisons were then made between the results of the simulation with the present mechanism and measured particle characteristics along the pathline of maximum soot. It was shown that the model accurately reproduced soot volume fraction, average number of soot aggregates, average primary particle diameter, and the average number of primary particles per aggregate along the pathline of maximum soot.

Further studies are needed to better understand the functional dependence of $\alpha$ on temperature and how that will affect soot modeling. However, the present work has shown that with $\alpha<1$, both inception-dominated and surface growth-dominated soot formation can be modeled accurately within a single system. With more accurate PAH formation in the present mechanism, the model does not require an unphysical boosting of surface growth to account for soot inception deficiencies. Further characterization of $\alpha$ should be conducted using a combination of theory, experiment and modeling. Toward that purpose, and to continue validating the model, application to a variety of systems, including combustion of $\mathrm{C}_{1}$, other $\mathrm{C}_{2}$, and larger alkane fuels, as well as non-paraffin compounds would provide additional insight. Special attention should be paid to systems in which soot formation and surface growth occurs over a wider range of temperatures, so that temperature effects can be better elucidated and characterized.

\section{Supplemental Material}

The present chemical kinetic reaction mechanism, thermodynamic data, and transport data are available from the authors (nadja.slavinskaya@dlr.de) upon request as supplemental material.

\section{Acknowledgements}

The authors acknowledge the Natural Sciences and Engineering Research Council of Canada and the Ontario Ministry of Research and Innovation for financial support. The authors would like to thank 
Prof. Tianfeng Lu at the University of Connecticut for his assistance in identifying reaction rates in the chemical kinetic mechanism that cause numerical stiffness. Computations were performed on the GPC supercomputer at the SciNet HPC Consortium. SciNet is funded by: the Canada Foundation for Innovation under the auspices of Compute Canada; the Government of Ontario; Ontario Research Fund - Research Excellence; and the University of Toronto.

\section{References}

1 B.S. Haynes, H.Gg. Wagner, Prog. Energy Combust. Sci. 7 (1981) 229-273.

2 K.H. Homann, Proc. Combust. Inst. 20 (1984) 857-870.

3 H. Bockhorn, (ed.), Soot Formation in Combustion: Mechanisms and Models, Springer-Verlag, Berlin, 1994.

4 E. Ranzi, Energ. Fuel. 20 (2006) 1024-1032.

5 F. Gelbard, J.H. Seinfeld, J. Coll. Int. Sci., 78 (1980) 485-501.

6 F. Gelbard, Y. Tambour, J.H. Seinfeld, J. Coll. Int. Sci., 76 (1980) 541-556.

7 M. Frenklach, Chem. Eng. Sci., 57 (2002) 2229-2239.

8 M. Frenklach, H. Wang, Proc. Combust. Inst. 23 (1990) 1559-1566.

9 M. Frenklach, Proc. Combust. Inst. 26 (1996) 2285-2293.

10 H. Wang, M. Frenklach, Combust. Flame 110 (1997) 173-221

11 J. Appel, H. Bockhorn, M. Frenklach, Combust. Flame 121 (2000) 122-136.

12 M. Balthasar, M. Frenklach, Combust. Flame, 140 (2005) 130-145.

13 H. Guo, G.J. Smallwood, Combust. Sci. Technol. 180 (2008) 1695-1708.

14 H. Guo, K.A. Thomson, G.J. Smallwood, Combust. Flame 156 (2009) 1135-1142.

15 R.J. Hall, M.D. Smooke, M.B. Colket, "Predictions of Soot Dynamics in Opposed Jet Diffusion Flames," in Physical and Chemical Aspects of Combustion: A Tribute to Irvin Glassman, R.F. Sawyer and F.L. Dryer, eds., 189-230, (Combustion Science and Technology Book Series, Gordon and Breach, Langhorne, PA, 1997).

16 C.S. McEnally, A.M. Schaffer, M.B. Long, L.D. Pfefferle, M.D. Smooke, M.B. Colket, R.J. Hall, Proc. Combust. Inst., 27 (1997) 1497-1505.

17 M.D. Smooke, R.J. Hall, M.B. Colket, J. Fielding, M.B. Long, C.S. McEnally, L.D. Pfefferle, Combust. Theor. Model., 3 (2004) 593-606.

18 M.D. Smooke, M.B. Long, B.C. Connelly, M.B. Colket, R.J. Hall, Combust. Flame, 143 (2005) 613-628.

19 S.D. Dworkin, M.D. Smooke, V. Giovangigli, Proc. Combust. Inst., 32 (2009) 1165-1172.

20 S.B. Dworkin, J.A. Cooke, B.A.V. Bennett, M.D. Smooke, R. J. Hall, M.B. Colket, Combust. Theor. Model., 13 (5) (2009) 795-822.

21 A. D'Anna, A. D'Alessio, J.H. Kent (cited as J. Kent), Combust. Flame, 125 (2001) 1196-1206.

22 A. D'Anna, J.H. Kent, Combust. Flame, 132 (2003) 715-722.

23 A. D'Anna, J.H. Kent, Combust. Flame, 144 (2006) 249-260.

24 A. D’Anna, J.H. Kent, R.J. Santoro, Combust. Sci. Technol., 179 (2007) 355-369.

25 A. D’Anna, J.H. Kent, Combust. Flame, 121 (2000) 575-592.

26 C.S. McEnally, L.D. Pfefferle, Combust. Flame, 152 (2008) 573-587.

27 R.J. Santoro, H.G. Semerjian, R.A. Dobbins, Combust. Flame, 51, (1983) 203-218.

28 Q. Zhang, M.J. Thomson, H. Guo, F. Liu, G.J. Smallwood, Combust. Flame, 156 (2009) 697-705.

29 Q. Zhang, H. Guo, F. Liu, G. Smallwood, M.J. Thomson, Proc. Combust. Inst., 32 (2009) 761-768.

30 Q. Zhang, Detailed Modeling of Soot Formation/Oxidation in Laminar Coflow Diffusion Flames, Ph.D. thesis, University of Toronto, Toronto, Canada, 2009.

31 M., Saffaripour, P., Zabeti, S.B., Dworkin, Q., Zhang, H. Guo, F. Liu, G. Smallwood, M.J. Thomson, Proc. Combust. Inst., 33, (2011) 601-608.

32 F. Xu, P.B. Sunderland, G.M. Faeth, Combust. Flame, 108 (1997) 471-493.

33 H. Böhm, H. Jander, D. Tanke, Proc. Combust. Inst., 27 (1998) 1605-1612 .

34 H. Böhm, H. Jander, Phys. Chem. Chem. Phys., 1 (1999) 3775-3781.

35 H. Böhm, K. Kohse-Höinghaus, F. Lacas, C. Rolon, N. Darabiha, S. Candel, Combust. Flame, 124 (2001) 127-136.

36 N.A. Slavinskaya, P. Frank, Combust. Flame, 156 (2009) 1705-1722.

37 N.A. Slavinskaya, U. Riedel, S.B. Dworkin, M.J. Thomson, "Detailed Numerical Modeling of PAH Formation and Growth in Non-Premixed Ethylene and Ethane Flames," in preparation (2010).

38 N.M. Marinov, W.J. Pitz, C.K. Westbrook, A.M. Vincitore, M.J. Castaldi, S.M. Senkan, Combust. Flame, 114 (1998) 192-213.

39 A.M. Vincitore, S.M. Senkan, Combust. Flame, 114 (1998) 259-266. 
40 N. Olten, S.M Senkan, Combust. Flame, 118 (1999) 500-507.

41 M.D. Smooke, V. Giovangigli, Int. J. Supercomput. Appl., 5 (1991) 34-49.

42 A. Ern, V. Giovangigli, D.E. Keyes, M.D. Smooke, SIAM J. Sci. Comput., 15 (1994) 681-703.

43 A. Ern, C.C. Douglas, M.D. Smooke, Int. J. Supercomput. Appl., 9 (1995) 167-186.

44 A. Ern, Vorticity-Velocity Modeling of Chemically Reacting Flows, Ph.D. Thesis, Yale University, New Haven, CT (1994).

45 H.A. van der Vorst, SIAM J. Stat. Comput., 13 (1992) 631-644.

46 R. Consul, C.D. Perez-Segarra, K. Claramunt, J. Cadafalch, A. Oliva, Combust. Theor. Model., 7 (2003) 525-544.

47 K. Claramunt, R. Consul, C.D. Perez-Segarra, A. Oliva, Combust. Flame, 137 (2004) 444-457.

48 J.A. Cooke, One- and Two-Dimensional Simulations of Diffusion Flames Using Complex Fuels and DistributedMemory Computing Clusters, Ph.D. Thesis, Yale University, New Haven, CT (2006).

49 M.R.J. Charest, C.P.T. Groth, O.L Gülder, Combust. Theor. Model., (2010) in press (doi:10.1080/1364783.2010.512960).

50 R.J. Santoro, T.T. Yeh, J.J. Horvath, H.G. Semerjian, Combust. Sci. Technol. 53 (1987) 89-115.

51 C.M. Megaridis, R.A. Dobbins, Proc. Combust. Inst. 22 (1988) 353-362.

52 C.M. Megaridis, R.A. Dobbins, Combust. Sci. Technol. 66 (1989) 1-16.

53 R. Puri, T.F. Richardson, R.J. Santoro, R.A. Dobbins, Combust. Flame 92 (1993) 320-333.

54 I.M. Kennedy, C. Yam, D.C. Rapp, R.J. Santoro, Combust. Flame, 107 (1996) 368-382.

55 C.S. McEnally, U.O. Köylü, L.D. Pfefferle, D.E. Rosner, Combust. Flame, 109 (1997) 701-720.

56 U.O. Köylü, C.S. McEnally, D.E. Rosner, L.D. Pfefferle, Combust. Flame, 110 (1997) 494-507.

57 A.G. Yazicioglu, C.M. Megaridis, A. Campbell, K.O. Lee, M.Y. Choi, Combust. Sci. Technol. 171 (2001) 71-87.

58 S.S. Iyer, T.A. Litzinger, S.Y. Lee, R.J. Santoro, Combust. Flame 149 (2007) 206-216.

59 H. Guo, F. Liu, G.J. Smallwood, O.L. Gulder, Combust. Flame 145 (2006) 324-338.

60 R. Puri, T.F. Richardson, R.J. Santoro, R.A. Dobbins, Combust. Flame 92 (1993) 320-333.

61 A.G. Yazicioglu, C.M. Megaridis, A. Campbell, K.O. Lee, M.Y. Choi, Combust. Sci. Technol. 171 (2001) 71-87.

62 S. H. Park, S. N. Rogak, J. Aerosol Sci., 35 (2004) 1385-1404.

63 S. H. Park, S. N. Rogak, W.K. Bushe, J.Z. Wen, M.J. Thomson, Combust. Theor. Model. 9 (2005) 499-513.

64 S.J. Harris, A.M. Weiner, Combust. Sci. Technol., 38 (1984) 75-84.

65 K.G. Neoh, J.B. Howard, A.F. Sarofim, Soot oxidation in flames, in Particulate Carbon: Formation During Combustion, Plenum, New York, 1981.

66 F. Liu, G.J. Smallwood, O.L. Gülder, J. Thermophys. Heat Transfer, 14 (2) (2000) 278-281.

67 N.M. Marinov, W.J. Pitz, C.K. Westbrook, M.J. Castaldi, S. Senkan, Combust. Sci. Technol., 116 (1996) 211-287.

68 K.J. Hughes, T. Turanyi, A.R. Clague, M.J. Pilling, Int. J. Chem. Kinet. 33 (2001) 513-538.

69 I.Gy. Zsély, J. Zádor, T. Turányi, Proc. Combust. Inst. 30 (2005) 1273-1281.

70 D.L. Baulch, C.T. Bowman, C.J. Cobos, R.A. Cox, Th. Just, J.A. Kerr, M.J. Pilling, D. Stocker, J. Troe, W. Tsang, R.W. Walker, J. Warnatz, J. Phys. Chem. Ref. Data 34 (3) (2005) 757.

71 S.P. Karkach, V.I. Osherov, J. Chem. Phys. 110 (1999) 11918-11927.

72 O.P. Shatalov, L.B. Ibraguimova, V.A. Pavlov, G.D.Smekhov, Y.V Tunik, "Analysis of the kinetic data described oxygen-hydrogen mixtures combustion," 4th European Combustion Meeting, 2009, p. 222.

73 A.D. Isaacson, J. Chem. Phys., 107 (1997) 3831-3839.

74 A.A. Konnov, Russ. J. Phys. Ch. B, 23 (8) (2004) 5-18.

75 X. Zhong, J.W. Bozzelli, Int. J. Chem. Kinet, 29 (1997) 893-913.

76 R.P. Lindstedt, K.A. Rizos, Proc. Combust. Inst. 29 (2002) 2291-2298.

77 L.K. Madden, A.M. Mebel, M.C. Lin, J. Phys. Org. Chem., 9 (1996) 801-810.

78 V.D. Knjazev, I.R. Slagle, J.Phys. Chem. A, 106 (2002) 5613-5617.

79 V.V. Kislov, A.M. Mebel, J. Phys. Chem. A, 111 (2007) 3922-3931.

80 P. Dagaut, G. Pengloan, A. Ristori, Phys. Chem. Chem. Phys., 4 (2002) 1846-1854.

81 C. Cavallotti, S. Mancarella, R. Rota, S. Carra, J. Phys. Chem. A, 111 (2007) 3959-3969.

82 K. Mati, A. Ristori, G. Pengloan, P. Dagaut, Combust. Sci. Technol., 179 (2007) 1261-1285.

83 H.Wang, M. Frenklach, Combust. Flame, 110 (1997) 173-221.

84 S.V. Patanker, Numerical Heat Transfer and Fluid Flow, Hemisphere, New York, 1980.

85 R.J. Kee, J.A. Miller, T.H. Jefferson, Chemkin: A General Purpose, Problem Independent, Transportable, Fortran Chemical Kinetics Code Package, Report SAND80-8003, 1980.

86 R.J. Kee, F.M. Rupley, J.A. Miller, A Fortran chemical kinetics package for the analysis of gas-phase chemical kinetics, Sandia Report SAND89-8009, 1989.

87 R.J. Kee, J. Warnatz, J.A. Miller, A Fortran Computer Code Package for the Evaluation of Gas-Phase Viscosities, Conductivities, and Diffusion Coefficients, Report SAND82-8209, 1983. 
88 R.J. Kee, G. Dixon-Lewis, J. Warnatz, M.E. Coltrin, J.A. Miller, A Fortran Computer Code Package for the Evaluation of Gas-Phase Multicomponent Transport Properties, Report SAND86-8246, 1986. 